*ak RMIS View/Frint Document Cover Sheet tow

This document was retrieved from the Documentation and Records Manaqement (DRM) ISEARCH System. It is intended for Information only and may not be the most recent or updated version. Contact a Document Service Center (see Hanford Info for locations) if you need additional retrieval information.

Accession \#: D196069090

Document \#: SD-WM-ATR-172

Title/Desc:

GAS CHARACTERIZATION SYSTEM SOFTWARE ACCEPTANCE TEST REPORT

Pages: 74 


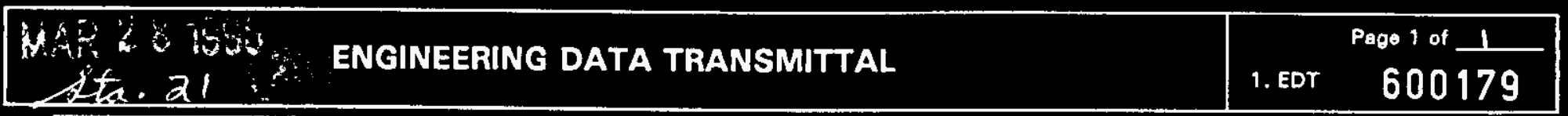

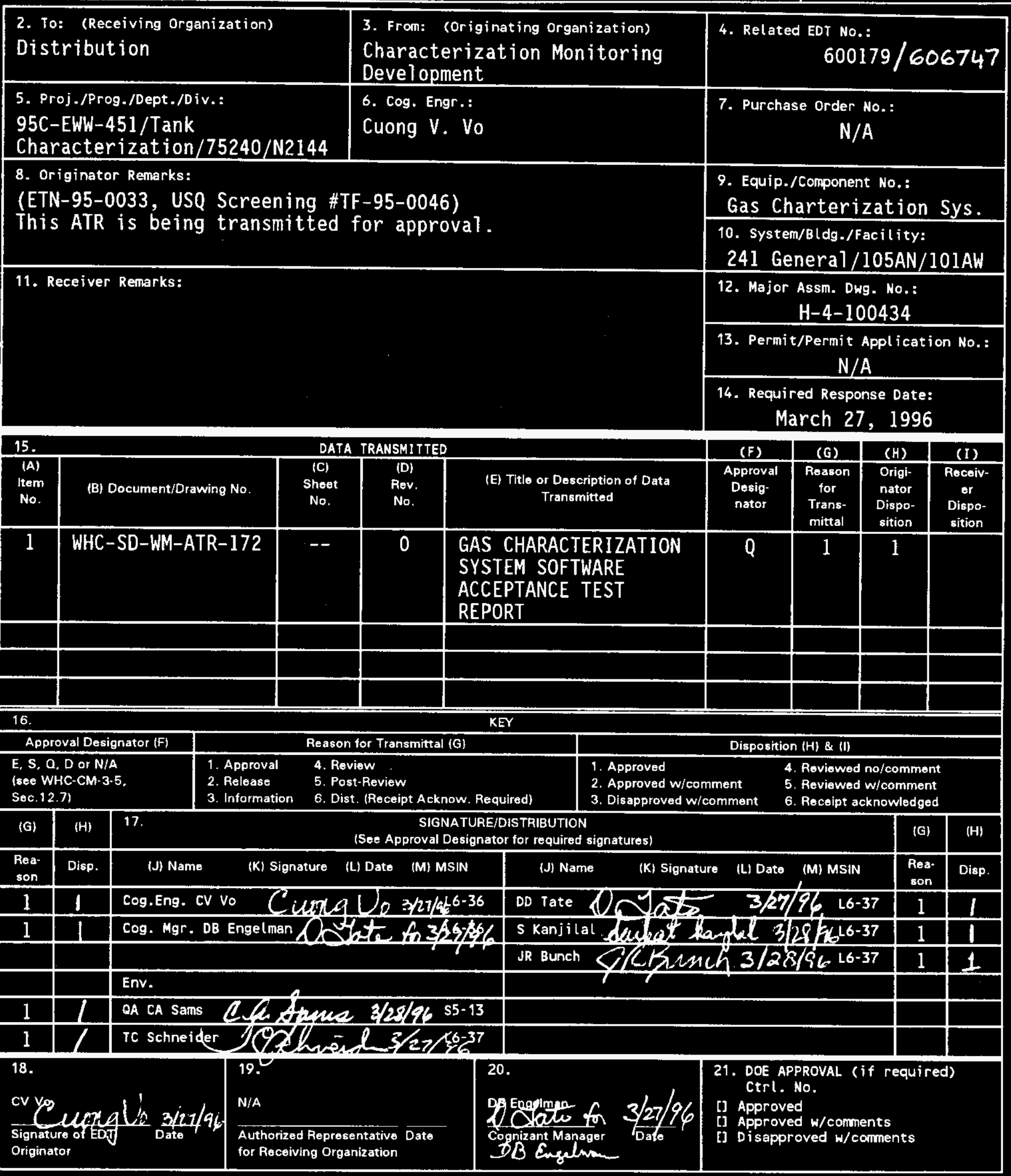

BD-7400-172-2 (04/94) GEF097 


\section{GAS CHARACTERIZATION SYSTEM SOFTWARE ACCEPTANCE TEST REPORT}

\section{Cuong V. Vo}

Westinghouse Hanford, Richland, WA 99352

U.S. Department of Energy Contract DE-AC06-87RL10930

$\begin{array}{lll}\text { EDT/ECN: } & 600179 & \text { UC: } 2030 \\ \text { Org Code: } & 75240 & \text { Charge Code: N2144 } \\ \text { B\&R Code: } & \text { EW3120072 } & \text { Total Pages: } 71\end{array}$

Key Words: Hydrogen, Ammonia, Nitrous 0xide, Methane, Gas Characterization, Software, Monitoring, Tanks, GCS.

Abstract: This document details the results of software acceptance testing of gas characterization systems. The gas characterization systems will be used to monitor the vapor spaces of waste tanks known to contain measurable concentrations of flammable gases.

TRADEMARK DISCLAIMER. Reference herein to any specific commercial product, process, or service by trade name, trademark, manufacturer, or otherwise, does not necessarily constitute or imply its endorsement, recommendation, or favoring by the United States Government or any agency thereof or its contractors or subcontractors.

Printed in the United States of America. To obtain copies of this document, contact: WHC/BCS Document Control Services, P.O. Box 1970, Mailstop H6-08, Richland WA 99352, Phone (509) 372-2420; Fax (509) 376-4989.
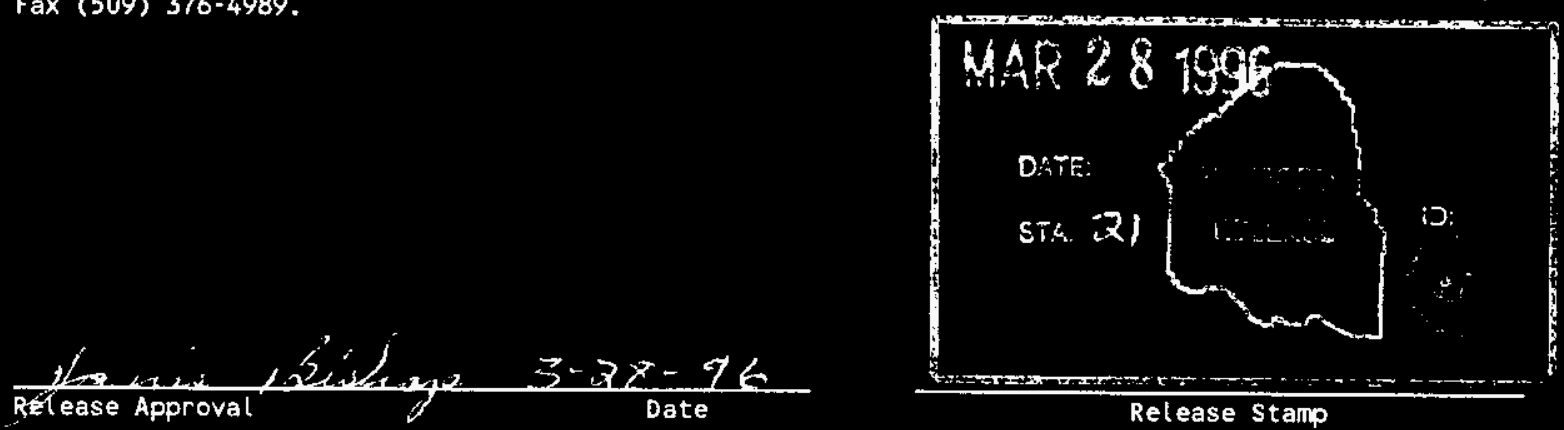

\section{Approved for Public Release}




\section{EXPCUTIVE SUMMARY}

\section{A. PURPOSE}

Acceptance Test Pxocedure WHC-SD-WM-ATP-172 was prepared to evaluate the software performance of a Gas Characterization System (GCS). The GCS will be used to measure the flammable gases which are contained in the vapor spaces of underground waste storage tanks. This Acceptance Test Report provides the detailed test results which verify that the software meets the functions and requirements as outlined in WHC-SD-WM-SFR-012, Rev.0, "Functional Requirements for Gas Characterization system Computer Software".

\section{B. TEST EXECUTION}

The software ATP for the GCS was performed in the High Bay of the 300 Area $306 \mathrm{E}$ facility. The software for the GCS system was satisfactorily tested and found to meet all the functional requirements with four noted exceptions. These exceptions were corrected by Engineering Changes Number 165030. The changes were a result of oversight during generation the Acceptance Test Procedure (ATP). These changes provided the minor correction to the procedure and did not change the intent of the ATP.

\section{c. CONCLUSION}

The software ATP for the GCS was successfully completed and the software meets all the acceptance criteria outlined in the Functional Requirements for the GCS software. The resolved ATP test exceptions do not affect the systems's performance or safety.

\section{DISPOSITION OF TESTED SYSTEMS}

The systems will be installed to monitor vapor space gases in the 200 Area waste storage tanks $241-\mathrm{AN}-105$ and $241-\mathrm{AW}-101$. 


\section{GAS CHARACTERIZATION SYSTEM SOFTWARE ACCEPTANCE TEST REPORT}

(WHC-SD-WM-ATR-172)

APPROVAL DESIGNATOR Q

Issued by

Characterization Monitoring Development

March 1996

Westinghouse Hanford Company 


\begin{tabular}{|c|c|c|c|c|}
\hline TITLE & PRINT NAME & SIGNATURE & INITIAL & DATE \\
\hline SYSTEM ENGINEER & $C \vee \vee O$ & lorea & $c W$ & $2 / 28 / 96$ \\
\hline TEST DIRECTOR & $C \vee \vee O$ & $x a V_{0}$ & CVV & $2 / 28 / a b$ \\
\hline TEST ENGINEER & JR BUNCH & & $7 \mathbb{B}$ & $2 / 28 \% 96$ \\
\hline
\end{tabular}

\begin{tabular}{|c|c|c|c|c|}
\hline \multicolumn{5}{|c|}{ TEBT FXECUTION } \\
\hline TITLE & PRINT NAME & SIGNATURE & INITIAL & DATE \\
\hline SYSTEY ENGINEER & 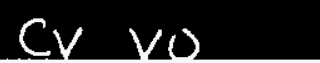 & na & cVu & $2 / 28 / 96$ \\
\hline TEST DIRECTOR & $C \vee \vee O$ & & $\mathrm{CVV}$ & $2 / 28 / 96$ \\
\hline TEST ENGINEER & $J R B$ & & $7 / \mathcal{B}$ & $2 / 28 / 96$ \\
\hline
\end{tabular}

\section{TEGT APRROVAT AND ACCEPHANCE}

Without Exception

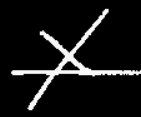

With Exception - Resolved ECN 165030

With Exception - Outstanding

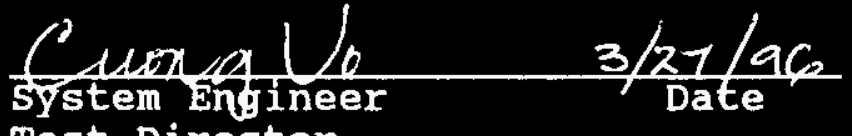

pest Director 
1.0 INTRODUCTION . . . . . . . . . . . . . . . . . . . 5

1.1 PURPOSE . . . . . . . . . . . . . . . . . 5

1.2 SCOPE . . . . . . . . . . . . . . . . 5

1.3 ACRONYMS . . . . . . . . . . . . . . . . . . . 5

2.0 SOFTWARE TEST PLAN . . . . . . . . . . . . . . . . . . . 5

2.1 PERSONNEL REQUIREMENTS • • • . • • • • • • • • • 6

2.1.1 System Engineer/Test Director . . . . . . . . 6

2.1 .2 Test Engineer . . . . . . . . . . . . . . 6

2.1.3 WHC Quality Assurance . . . . . . . . . . . 7

2.1.4 others..................... 7

2.2 TEST CONDITIONS . . . . . . . . . . . . . . . . 7

2.2 .1 Test Conditions . . . . . . . . . . . . . 7

2.2.2 Safety . . . . . . . . . . . . . . . . . . . 7

2.3 ACCEPTANCE TEST PROCEDURE CHANGE CONTROL . . . . . 7

2.3.1 Major Procedure Change . . . . . . . . . . . 7

2.3.2 Minor Procedure Change . . . . . . . . . . . 8

2.4 TEST EXECUTION . . . . . . . . . . . . . . . . . 8

2.4.1 Without Exception . . . . . . . . . . . . . 8

2.4.2 With Exception/Resolved . . . . . . . . . . . 9

2.4.3 With Exception/Outstanding . . . . . . . . . . 9

2.5 RECORDING AND RESOLVING EXCEPTIONS . . . . . . . . 9

2.5.1 General . . . . . . . . . . . . . . 9

2.5.2 Recording . . . . . . . . . . . . . . . . 9

2.5.3 Approval and Acceptance . . . . . . . . . . . 9

2.5 .4 Distribution . . . . . . . . . . . . . . . . 10

3.0 SOFTWARE FUNCTIONS . . . . . . . . . . . . . . . . . . . 10

3.1 LabView DATA ACQUISITION CONTROL SYSTEM . . . . . . 11

3.1.1 Operator Interface Control and Indicator

$\cdot \cdot \cdot \cdot \cdot \cdot \cdot \cdot \bullet \cdot \bullet \cdot \bullet \cdot \cdot 11$

3.1.3 HLAN network failure mode . . . . . . . . . . 11

3.1.4 GCs Calibration Control Function . . . . . . . 11

3.2 GAS CHROMATOGRAPH 1 AND 2 DATA SYSTEMS . . . . . . 11

3.2.1 EzChrom 200 Data Systern Function . . . . . . . 12

3.2.2 Organize and Format EZChrom Data . . . . . . . 12

3.2.3 Organize Data Following a System Outage or

3.2.4 Interface with Labview VI . . . . . . . . . . 12

3.2.5 Data Compression and HLAN Transfer . . . . . . 12

3.2.6 Data Handing During Network Outage . . . . . 12

3.3. FTIR DATA SYSTEM . . . . . . . . . . . . . . . . . 12

3.3.1 Win-IR Data System Function . . . . . . . . . 12

3.3.2 Organize and Format Win-IR Data . . . . . . . 13

3.3.3 Organize Data Following a System Outage or
Date Change . . . . . . . . . . 13

3.3.4 Data Compression and HLAN Transfer . . . . . . 13

3.3.5 Data Handling During Network Outage . . . . . 13 


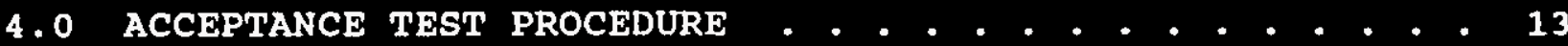

4.1 INITIAL SETUP . . . . . . . . . . . . . . . . . . . 13

4.2 LabVIEW VIRTUAL INSTRUMENT DATA SYSTEM . . . . . . 15

4.2.1 Test Preparation . . . . . . . . . . . . . . 15

4.2.2 ON/OFF Switch Control Test... . . . . . . . 16

4.2.3 Process Instruments Readouts . . . . . . . . . 16

4.2.4 Record Data To File Control . . . . . . . . . 18

4.2.5 Record Data Rate Control Input . . . . . . . . 19

4.2.6 Data File Content . . . . . . . . . . . . 20

4.2.7 Data Transfer Across HLAN . . . . . . . . . . 20

4.2.8 Local Data storage In The Event of HLAN

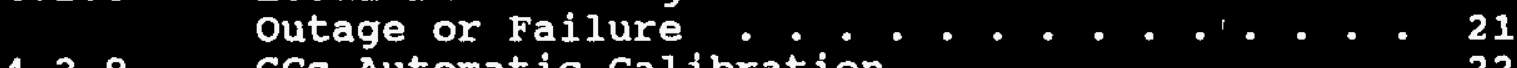

4.2.9 GCs Automatic Calibration . . . . . . . . . . 22

4.3 GC1 DATA SYSTEM - . • . . . . . . . . . . . . 24

4.3.2 Test Preparation $\dot{4}$.

4.3.3 Retrieve, Organize and Format Data Generated

In EzChrom . . . . . . . . . . . . . . . 25

4.3.4 Append Data After Restart And Day Change
Verifications . . . . . . . . . . 27

4.3.5 Calibration and Display Interface Between

LabView VI and GC1 Data Acquisition

4.3.6 Compress And Transfer GC1 Data Across HLAN . - 31

4.3.7 Data Handing Capabilities During Network

4.4 GC2 DATA SYSTEM

4.4.1 Test Preparation . . . . . . . . . . . . . . 35

4.4.2 Verify The Operation EzChrom 200 Data System . 35

4.4.3 Retrieve, Organize and Format Data Generated

4.4.4 Append Data After Restart And Day Change

LabView VI and GC2 Data Acquisition

4.4 .6

Application . . . . . . . . . . . . . 39

4.4.7 Data Handling Capabilities During Network

4.5 FTIR DATA SYSTEM . . . . . . . . . . . . . . . 46

4.5.1 Test Preparation . . . . . . . . . . . . 46

4.5.2 Normal Mode Test . . . . . . . . . . . . 46

4.5.3 Interrupted Mode Test . . . . . . . . . . . 48

4.5.4 Day Change Test . . . . . . . . . . . . . . . 48

4.5.5 Transfer Data Accross HLAN . . . . . . . . . . 49

4.5.6 Network Failure Test . . . . . . . . . . . . . 51

4.6 TEST APPROVAL AND ACCEPTANCE . . . . . . . . . . . 53

5.0 TEST RECORD SHEETS . . . . . . . . . . . . . . . 53

5.1 TEST EXCEPTION SHEET . . . . . . . . . . . . . . . 53

5.2 TEST LOG SHEET . . . . . . . . . . . . . . . . . . 53

APPENDIX A: TEST EXCEPTION SHEETS . . . . . . . . . . . $65(45$ HETS

APPENDIX B: TEST LOG SHEET . . . . . . . . . . . . . . $66(1$ SHET) 


\section{CAB CRARACTERIZATION BYgTHE \\ BOFTWARE ACCEPTAYCE TEST PROCFDURE}

\subsection{INRRODUCTIOS}

\subsection{PURPOBE}

This document serves as both the software test plan and software acceptance test procedure for testing the software that was developed to operate the gas characterization system (GCS). Together with the forthcoming acceptance test report, this document satisfies the requirements in the EP (WHC-CM-6-1), "Design Verification Requirements". The selected method of design verification is qualification testing.

\section{$1.28 \mathrm{COPB}$}

The testing described in this document covers the software that controls and acquires data for the gas characterization system. In addition to the software, this testing will verify and validate the data acquisition and control hardware for the GCS. Separate ATPs will be prepared for the hardware features not related to software.

$\begin{array}{ll}\text { 2.3 ACROwYYs } \\ \text { GCS } & \text { Gas Characterization System } \\ \text { ATP } & \text { Acceptance Test Procedure } \\ \text { ATR } & \text { Acceptance Test Report } \\ \text { EP } & \text { Standard Engineering Practice (WHC-CM-6-1) } \\ \text { SFR } & \text { Software Functional Requirements } \\ \text { WHC } & \text { Westinghouse Hanford CompanY } \\ \text { GC1 } & \text { Gas Chromatograph } 1 \\ \text { GC2 } & \text { Gas Chromatograph } \mathbf{2} \\ \text { FTIR } & \text { Fourier Transform Infra-Red } \\ \text { NI } & \text { National Instrument } \\ \text { VI } & \text { Virtual Instrument } \\ \text { MTI } & \text { Microsensor Technology Inc. } \\ \text { HLAN } & \text { Hanford Local Area Network } \\ \text { QA } & \text { Quality Assurance }\end{array}$

\subsection{BOFTWARE TEBT PHAY}

The software acceptance test defined by this document will test the features of the software described in WHC-SD-WM-SFR-012, Rev.0, "Functional Requirements for Gas Characterization system Computer Software". A comprehensive software test will test every feature based on the functional details listed in section 3. Related hardware will be indirectly tested. 


\subsection{PERBOWNEL REQUIREYENTB}

Each organization participating in the conduct of this test will designate personnel to assume the responsibilities and duties as defined within their respective roles. The names and signatures of these people shall be provided to the rest ingineer for listing on the Test Engineer's copy of the Test Execution sheet prior to the performance of any part of this test.

\subsubsection{Bystem Engineer/Teat Director}

The System Engineer/Test Director's responsibilities are as follows:

- Assume responsibility for the performance, preparation, and adequacy of the test.

- Notify all interested parties when a change is made in the testing schedule.

- Take necessary action to clear exceptions to the ATP.

- Determine if the changes to ATP are classified as Major or Minor.

- Sign Test Execution sheet when ATP is approved and accepted.

- Sign Exception sheet when exception has been resolved.

2.1.2 Test Engineer

The Test Engineer's responsibilities are as follows:

- The engineer will perform the test. The system Engineer/Test Director may also serve as a Test Engineer.

Verify the instruments are in current calibration.

- Perform the test as described in this document.

- Stop any test which, in the judgment of the Test Engineer, may cause damage to the system or present an unsafe condition.

- Coordinate efforts with all other assigned test performance team members.

- Observe the test and record test data.

- Record exceptions and test steps which are not performed. 
- Sign Test Execution Sheet when ATP has been performed.

- Sign Exception Sheet when exceptionable retest has been performed or exception cleared.

\section{1 .3 Wre Quality Assurance}

The WHC QA organization responsibilities are as follows:

- Review and approve ATP.

- Verify that all testing has been completed by review and approve the Acceptance Test Report (ATR).

- Review and approve any Major procedure changes. See section 2.3 for definition of Major and Minor procedure changes.

\section{1 .4 others}

No further witnesses are required during testing but interested observers will be allowed.

\subsection{TFBT CONDITIONS}

\subsubsection{Tast condtions}

- All software testing will be performed in the WHC building $306 \mathrm{E}$ laboratory.

- HLAN network arop shall be available.

AC power for the GCS shall be available.

\subsubsection{Bafety}

A specific Job Hazard Analysis Checklist shall be prepared and approved prior to acceptance testing. A prejob safety briefing shall also be conducted with all test personnel by the system Engineer/Test Director.

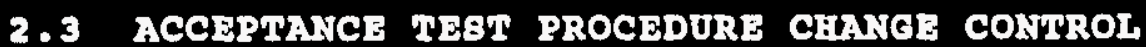

Acceptance testing shall be conducted in accordance with the steps and requirements specified in this procedure. Field changes may be incorporated into the test procedure and are designated as either Minor or Major.

\section{3 .1 Major Procedure Chango}

A major procedure change is defined as any change which affects the scope, intent or quality of the acceptance test procedure. Major field changes require written approval of 
the System Engineer, Test Director, and WHC Quality Assurance. Major field changes shall also be recorded as a test exception.

\subsubsection{Minor Procedure Change}

A minor procedure change is defined as a change which does not affect the intent of the acceptance test procedure. Typically minor changes involve procedure clarifications or changes to the sequence of test steps to facilitate conduct of testing. Minor field changes can be made in pen and ink and require approval of the system Engineer/Test Director.

\subsection{TEBT EXFCUTIOS}

The acceptance test procedure detailed in section 4 shall be performed in sequential steps starting with section 4. The Test Director/System Engineer may direct performance of major sections of the procedure out of sequence if the testing does not compromise the intent of the ATP. The Test Engineer will check mark every test step and verify readings are recorded in the spaces provided as each step is completed.

It is the intent to perform this procedure uninterrupted from beginning to end. If the testing is terminated due to time constraints, the Test Director will determine the appropriate test termination point and the terminated test configuration will be noted in the Test Log. The test will restart at the next shift by reestablishing the noted test configuration. If testing is terminated due to a Test Exception, the system will be placed into a safe configuration and noted in the Test Log if testing cannot continue until the Test exception is resolved. If testing may continue, the initial conditions will be established per the next test section. Upon Test Exception Resolution, the test configuration noted in the Test Log will be reestablished and the appropriate sections of the test will be re-performed per the Test Exception Resolution requirements.

\subsubsection{Without Exception}

- Check applicable space on the test procedure to show that the ATP has been performed and no exceptions have been recorded.

- Sign and date Text Execution Sheet in the spaces provided.

- Distribute requisite copies and send master of ATP to the ATR preparer. 


\section{4 .2 With Exception/Resolved}

- Check applicable space on Test Execution sheet to show that the ATP has been performed with exceptions recorded and resolved.

- Sign and date Test Execution Sheet in the spaces provided.

- Distribute requisite copies and send master of ATP to the ATR prepare.

\subsubsection{With Exception/Outstanding}

- Check applicable space on Test Execution sheet to show that the ATP has been performed with exceptions recorded, part or all of which are presently outstanding, unresolved.

- Sign and date Test Execution sheet in the spaces provided.

- Distribute requisite copies and send master of ATP to the ATR prepare.

\subsection{RECORDINe AND REBOLVINE EXCEPTIONB}

\subsubsection{General}

Exceptions to the ATP are sequentially numbered and recorded on individual Exception Sheets. This enables case-by-case resolution, recording, approval, and distribution of each exception.

\section{5 .2 Recording}

- Number each exception sequentially as it occurs and record it on an Test Exception sheet.

- When action taken results in an acceptable retest, sign and date Retest Execution and Acceptance section of the Exception Sheet.

- When action taken does not involve an acceptable retest, strike out the Retest Execution and Acceptance section of the Exception Sheet. Resolve exception as shown under 2.5 .3 below.

\subsubsection{Approval and Accoptanco}

- The System Engineer provides final approval and acceptance of exception by checking one of the following on Exception sheet: 
- Retest Approved and Accepted: Applicable when Retest Execution and Acceptance section is completed.

- Exception Accepted-As-Is: Requires detailed explanation.

- Other: Requires detailed explanation.

- The System Engineer signs and dates the Bxception sheet and obtains other internal approval, if required.

\subsubsection{Distribution}

Distribute requisite copies of completed Exception Sheets to the ATR prepare.

\subsection{BOTTWARE FUNCTIONB}

The GCS computer system consists of several individual computer components necessary to provide control and data acquisition functions for the GCS analytical instruments. Two gas chromatograph instruments (GC1 computer and GC2 computer) are used to monitor Hydrogen, Nitrous oxide, and Methane in the tank vapor space. The FTIR instrument (FTIR computer) monitors Ammonia content in the same gas stream.

The GC1, GC2 and FTIR computers are networked to the host computer GCS1HOST using the Microsoft Windows NT multi-tasking operating system and networking software. (Note: Currently, for the two systems being installed, the Host computer for the first system will be designated GCS1HOST and the Host computer for the second system will be designated GCS2HOST. This document will refer to the Host computer as GCS1HOST). This allows the system components to function in parallel to control the instruments, sensors, and electric valves. Additionally, the computers must perform mathematical functions (i.e. integrate the area under the curve) to produce "Calculated concentrations". Controlling the instruments with these microcomputers, requires not only vendor supplied software, but also configuration, automation, and integration programming. Integration software consists of several systems. Labview VI system provides process data acquisition and control of the automatic calibration feature for the gas chromatograph instruments. GC1 and GC2 software systems provide an automated process for data configuration and handling. A modified vendor supplied software version (Win-IR) gives the FTIR the capabilities of continuous sampling and data configuration.

\footnotetext{
$I_{\text {Windows }}$ is a trademark of Microsoft Corporation

LabView is a trademark of National Instruments Corporation
} 


\subsection{IAbVION DATA ACQUIBITION CONTROL BYBTEY}

\subsubsection{Operator Interface control and Indicator Function}

- Provide real time display on front panel for process data such as pressure, flow, and temperature.

- Accept control inputs from front panel for data file recording and gas chromatographs calibration. Details to these control inputs will be described in section 3.2 .2 and 3.2 .4

\subsubsection{Data File Recording and Archiving Funotion}

- Data files will be logged based on the file configuration control inputs as follows:

- Requires complete archive path.

- Data frequency.

- Toggle button to Save or Not Save to file.

- The process data file will be automatically generated once at the beginning of each day and uniquely named using a date stamp.

- At the beginning of each day, the data file of the previous day will be archived across the HLAN per the predefined archive path.

3.1.3 HLAN network failure mode

- Data will be preserved by saving locally.

- Provide adequate data storage for a minimum of one week.

\subsubsection{GCs calibration control Function}

- Accept calibration control inputs on front panel as follows :

- Time start

- Duration

- Provide signals to control auto calibration valves.

- Mark data file to identify calibration sample.

\subsection{GAS CHROMATOERAPH 1 AMD 2 DATA BYBTEYB}

The GC1 and GC2 data systems are design to have the same funtionality except that GC1 measures hydrogen gas and GC2 measures methane and nitrous oxide gases. 


\subsubsection{EqChrom 200 Data 8ystem Function}

- Controls and aquires data from MTI Gas Chromatograph. Software is vendor suppied.

- User defined method programs are used to analyze chromatogram data and calculate component concentrations.

\section{2 .2 Organize and Format Bzchrom Data}

- Custom software (GC1APP32.EXE and GC2APP32.EXE) collects and organizes EzChrom data.

- Organized by date

- Organized by run or index number

3.2.3 Organize Data Following a Byatem Outage or Date Change

Software automatically indexes filenames following a system outage or upon date change.

\subsubsection{Interface with Iabvien VI}

- Data from GCs is passed to and displayed in Labview.

- Calibation data is flagged based upon external valve operation initiated fxom Labview.

\subsubsection{Data Compression and HAM Transer}

- At a pre-defined time each day, all GC data will be compressed and sent to archive over HLAN connection.

\subsubsection{Data Ianding During Notwork Outage}

- System is required to store archive data locally in the event of a network failure or interruption.

3.3. PTIR DATA BYBTHY

\subsubsection{Win-IR Data Bystem Function}

- Controls and aquires data from BIO-RAD Infra-Red Spectrometer. Software is vendor suppied.

- User defined method programs are used to analyze interferogram data and calculate component concentrations. 


\subsubsection{Organize and Format win-IR Data}

- Custom software with modified vendor supplied software continuous collects and organizes data.

- Organized by date

- Organized by index number in sequential order

$3 \cdot 3 \cdot 3$ Organize Data Following a system Outage or Date
Change

- Software automatically indexes filenames following a system outage or upon date change.

\subsubsection{Data Compression and BLAY Transfer}

- At a pre-defined time each day, all FTIR data will be compressed and sent to archive over HLAN connection.

\subsubsection{Data Handing During Network Outage}

- System is required to store archive data locally in the event of a network failure or interruption.

\subsection{ACCEPTAYCE TEAT PROCEDURE}

The Test Engineer is expected to be familiar with windows operating system, WindowsNT operating system, LabView VI, EZChrom data system, and Win-IR data system.

The following procedure defines the testing that will be performed. If any step cannot be successfully performed or results in an abnormal condition, record a description of the condition in the test $\log$ and prepare a Test Exception to track the probem resolution.

For each test exception recorded, enter an identifying number in the "EXCEPTION NUMBER" Column of the Test Exception sheet attached.

Reproduce Test Exception sheet as needed, and attach the additional pages to this procedure, to record all test exceptions noted during testing.

\subsection{INITIAT BETUP}

The following procedure describes steps for setting up the GCS systems. Since all data is transferred via HhAN to the 300 Area Data Server (LABHOST), a prerequisite to this procedure is to ensure that LABHOST is ON and connected to the network.

BTFP 1:
Ensure that all instruments (GC1, GC2, FTIR, and Process 
Instruments) are powered up. Power up all computer systems in the following sequence GC1, GC2, GCS1HOST, and FTIR.

NOTE: Sequence of Start-Up of these computer systems is critical to ensure proper establishment of network communications.

with the exception of GCS1HOST all systems share a common monitor/keyboard/mouse which is activated by depressing the buttons on the switching module.

BMPP 28

$\$ \quad$ Log-on to all computer systems. Logon scripts are required. Contact system administrator or test engineer for password list.

8TBP 3:

W On the ccsirost computer, verify that the following shares and network drives are connected.

NOTE: The name and location these drives is critical to proper system operation.

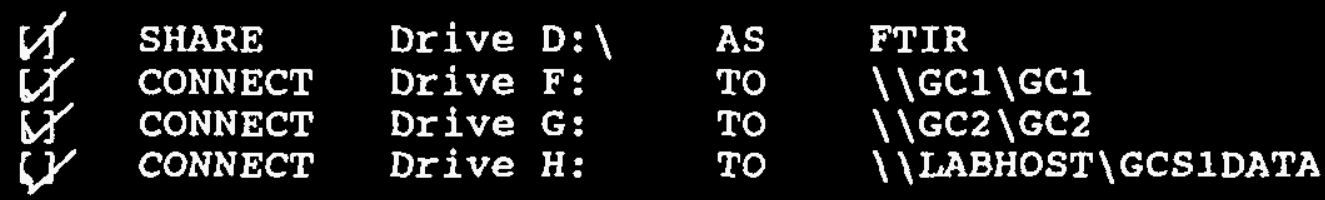

If shares and network drives do not exist and network shares cannot be establish or network drives cannot be connected, please consult with system Administrator or system Engineer to resolve these problems.

\section{BTFP 48}

G On the FTIR computer, verify that the following network drive is connected.

CONNECT Drive D: |/GCS1HOSTIFTIR

If shares and network drives do not exist and network shares cannot be establish or network drives cannot be connected, please consult with system administrator or system engineer to resolve these problems.

NOTE: The name and location these drives is critical to proper system operation.

8TSP $5:$

d) Synchronize GCS1HOST, GC1, GC2, and the FTIR computer systems to the current time and date.

BTFP 6:

Instrumentation and computer equipment involved in the test 
is at ambient operating temperature between $20^{\circ} \mathrm{C}$ and $25^{\circ} \mathrm{C}$.

\subsection{LabVIOW VIRTUAT INBTRULENT DATA BYBTEY}

NOTE :

EQUIPMENT AND INSTRUMENT DESIGNATOR DEFINITION:

EXAMPLE: $\quad \frac{\text { FIT }}{A}-\frac{\hbar}{B}-\frac{Y}{C}$

A. EQUIPMENT/INSTRUMENT IDENTIFIER PER H-14-020000

B. ONE OR TWO DIGIT TANK FARM LOCATION NUMBER $(1=\mathrm{AN}, 31=\mathrm{SY})$

C. TWO DIGIT SEQUENTIAL, LOOP OR DEVICE IDENTIFIER

D. ALPHA CHARACTER TANK IDENTIFIER

\subsubsection{Teat Preparation}

\section{BTEP 1:}

Verify that the GCS1HosT computer analog I/O card is connected to the AMUX card in the Analog drawer.

\section{BTEP 2:}

Verify that the GCS1HOST computer serial card is connected to the 5B digital card in the Discrete drawer.

\section{BTEP $3:$}

Verify that all process instruments, which will be processed by LabView GCSVI.VI, are powered up per the Test Director's instruction.

\section{BTEP 4:}

Place the gas delivery system into normal operating conditions under System Engineer's direction with the following parameter settings.

MAIN SAMPLE FLOW:

GC1 SAMPLE FLOW:

GC2 SAMPLE FLOW:

$$
\begin{aligned}
& 0.5 \mathrm{CFM} / 2.5-3.0^{\prime \prime} \mathrm{H}_{2} \mathrm{O} \\
& 5-10 \mathrm{CC} / \mathrm{M} \\
& 5-15 \mathrm{CC} / \mathrm{M}
\end{aligned}
$$

\section{BTEP $5:$}

Y

on the GCS1HOST computer, close all active windows under Program Manager.

BTEP 6:

¿ start Labview program by selecting "GCSVI" icon from GCSAPPS group.

\section{BTFP 7:}

(1) Verify that the cCSVI.VI front panel is displayed on the GCS1HOST computer.

\section{THP 8:}

$\$ 6$ Click on the LabView continuous run button to run GCSVI.VI application. 


\subsubsection{Oy/OrE Bwitoh control Test}

\section{BTEP 18}

set front panel controls as follows:

FILE CONFIGURATION:

$\begin{array}{llll}* & \text { ARCHIVE PATH: } & \text { H: } \backslash N I & \text { (DEFAULT) } \\ \text { * LOG INTERVAL SEC: } 60 & \text { (DEFAULT) } \\ \text { * RECORD DATA: } & \text { PUSH TO SAVE }\end{array}$

GC1 NT-20

CALIBRATION

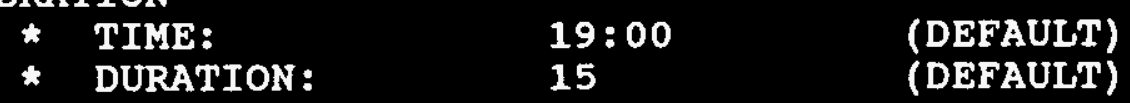

GC2 NT-30

CALIBRATION

$\begin{array}{lll}\text { * TIME: } & 20: 00 & \text { (DEFAULT) } \\ \text { * DURATION: } & 15 & \text { (DEFAULT) }\end{array}$

BTEP 2:

$\$$ Toggle the ON/OFF switch to ON position and visually verify that the GCSVI.VI strip chart recorder is started.

\section{TEP 38}

4 Toggle the ON/OFF switch to OFF position and visually verify that the GCSVI.VI strip chart recorder is stopped.

\subsubsection{Process Instruments Readouts}

BTEP 18

C) Toggle the ON/OFF switch to ON position.

8TFP 2: (Pressure and Flow instruments)

a Record and verify that the instrument LCD display and the "GCSVI.VI" window display agree within $5 \%$ for each instrument 11sted on TABLE 4.2.3.1.

8TFP 3: (Pressure and Flow instruments)

1 Establish different instruments readings by decreasing or increasing main sample flow control valve FCV-*13 per the System Engineer's direction.

4 Repeat STEP 2.

8TBP 4: (Temperature instruments)

(Y) Open the JBX-*10 FU-5.

(1) Verify that the LED display on the temperature transmitter TIT $-\star 40$ and the display on GCS1HOST computer agree within $\$ 5$.

ty Record both readings into TABLE 4.2 .3 .2 for TIT- $\$ 40$. 
8T5P 5: (Temperature instruments)

Close the $\mathrm{JBX}-* 10 \mathrm{FU}-5$.

Verify that the LED display on the temperature transmitter TIT-*11 and the display on GCS1HOST computer agree within

$\$ 5$.

U Record both readings into TABLE 4.2 .3 .2 for $T I T-\star 11$.

GTFP 6: (Temperature instruments)

(1) Record and verify that the LED display on the temperature controller TIC $-* 10$ is indicating the expected temperature.

Indicated temp: $\quad 79$

8TER 7: (Temperature instruments)

Adjust the TIC-*10 low temperature alarm set point 2, to 10 degrees $p$ nxw the indicated temperature.

LYzilak ABCve

Indicated temp: $\frac{79}{\text { Alarm set point } 2 \text {. } 89}$

BTEP 8:

4 Record the TIC- 10 alarm status displayed on the window "GCSVI. VI".

Expected Result: ALARM

GCSVI.VI status: $\triangle L A R M$

8TFP $9:$ (Temperature instruments)

Adjust the TIC- 10 low temperature alarm set point 2 , to 10 degrees Aporz the indicated temperature. CVial Belou

Indicated temp: $\frac{79}{29}$

BTEP 10:

Record the TIC- -10 alarm status displayed on the window "GCSVI.VI".

Expected Result: NORMAL

GCSVI.VI status: NorMal

BTFP $11:$

(1) Verify that the GC1_VI.DAT and GC2_VI.DAT files exist on GCS1HOST computer.

(U) C: IGC1_VI.DAT

(U) C: $1 \mathrm{GC2}$ VI.DAT

8THP 12:

M Open the C:IGC1 VI.DAT file and record the following data into TABLE $4.2 \cdot \overline{3} \cdot 3$

ROW 1 is H2-LO PPM

ROW 2 is H2-HI PPM 
BTEP 13:

Open the C: IGC2 VI.DAT file and record the following data into TABLE $4.2 \cdot \overline{3}, 4$

ROW 1 is CH4-LO PPM

ROW 2 is N2O-LO PPM

ROW 3 is CH4-HI PPM

ROW 4 is N20-HI PPM

M RTEP 14:

Record the H2-LO PPM and the H2-HI PPM displayed on GCSVI.VI window into TABLE 4.2.3.3 under GCSVI.VI READING column.

\section{BTEP 15:}

(1) Record the CH4-LO PPM, N20-LO PPH, CH4-HI PPM, and N2O-HI PPM displayed on GCSVI.VI window into TABLE 4.2.3.4 under GCSVI.VI READING column.

\subsubsection{Record Data To File Control}

\section{BTFP $1:$ \\ 4 Verify that the PUSH TO SAVE/LOG TO FILE push button is in} PUSH TO SAVE position.

\section{TFP 2:}

4 Set the record data rate value to:

LOG INTERVAL SEC $=1$ SEC

\section{BTFP 3:}

$M$ Remove all subdirectories and files under the GCS1HOST data directory "D: \NI".

\section{BTDP 4:}

$M$ Click on the PUSH TO SAVE button to toggle to the LOG TO FILE position.

\section{BTER 5:}

4 In File Manager verify that the file "Y-MM-DD-VI.RPT" exist in the directory "D: INI", where Y-MLY-DD is the current year, month, and day.

\section{BTEP $6:$}

In GCSVI.VI window, push the LOG TO FILE button to toggle to the PUSH TO SAVE position.

NOTE: DO NOT attempt to adjust the temperature, pressure, and flow controls during testing in section 4.2 .5 . and 4.2 .6 . 


\subsubsection{Recora Data Rate Control Input}

\section{TFP 1:}

Verify that the PUSH TO SAVE/LOG TO FILE push button is in PUSH TO SAVE position.

\section{BTFP 2:}

Set the record data rate value to:

LOG INTERVAL SEC $=60$ SEC

\section{BTEP 38}

(t) Remove files under directory D: WNI if they exist.

\section{BTEP $4:$}

(r)

In the GCSVI.VI window, push the pusH To SAVE button to toggle to LOG TO FILE position.

\section{TFP 58}

(1) Wait approximately for five to six minutes before proceeding.

Ut Set the data rate value to:

LOG INTERVAL SEC $=120$ SEC

\section{STEP 7:}

Wait approximately for five to six minutes before proceeding.

\section{TBP 8:}

a In the GCSVI.VI window, push the LOG TO FILE button to toggle to the PUSH TO SAVE position.

\section{TEP 9:}

$M$ In File Manager verify that the file "Y-MM-DD-VI.RPT" exist in the directory "D: INI", where Y-MM-DD is the current year, month, and day.

\section{TEP 10:}

$M$ Use a text editor to view the file "D: INI IY-MM-DD-VI.RPT" where $Y-M M-D D$ refers to the year, month and day of today's date.

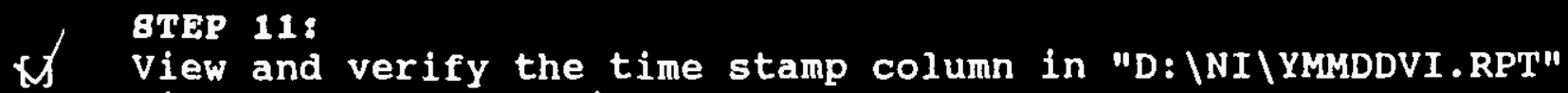
file for the following:

M 1 MIN (+-) 1 MIN increments between two consecutive data records, for the first four to five minutes.

M 2 MIN (t-) 1 MIN increments between two consecutive data records, for the second four to five minutes. 


\subsubsection{Data File Content}

BTEP 18

M Use a text editor to view the file "D: |NI |Y-MM-DD-VI.RPT" where $Y-M M-D D$ refers to the year, month and day of today's date.

\section{BTEP $2:$}

$M$ Verify the header information in the file by checking each match in the TABLE 4.2.6.1.

\section{BTSP 38}

\section{Mecord the last data record to the TABLE 4.2.6.2.}

M Close text editor and switch back to GCSVI.VI application.

(1) Record process instrument displayed on GCSVI.VI to the TABLE 4.2 .6 .2 .

M Verify that the recorded data match the instrument displays on the front panel listed on TABLE 4.2.6.2. (agree within 5\%)

\subsubsection{Data Transfer Across HWA}

$M$ Use the File Manager to remove all files under data directory $\mathrm{H}$ : INI, if files exist.

\section{BTEP $2:$}

If In the GCSVI.VI window, verify that the archive path

contained $\mathrm{H}$ : INI

M Set LOG INTERVAL SEC to 2 seconds.

\section{BTEP 38}

In the GCSVI.VI window, push the PUSH TO SAVE button to toggle to the LOG TO FILE position.

\section{BTEP 4:}

M Under Program Manager set the GCS1HosT system date to the next day's date.

\section{STEP $5:$}

M Allow 3 minutes before proceeding. BTEP 6:
In File Manager verify that the file "H: INI YY-MM-DD-VI.RPT"
of the previous day exists. 
BTFP 7:

In File Manager verify that the file "D: NNI YY-MM-DD-VI.RPT" was generated and the file of the previous day was deleted.

BTEP 8:

[1 In the GCSVI.VI window, push the LOG TO FILE button to toggle to the PUSH TO SAVE position.

\section{BTPP $9:$}

W Under Program Manager set the GCS1HOST system date back to today's date.

\subsubsection{Looal Data storage In the Event of Mms outage or Failure}

\section{BTaP $1:$}

$M$ Use the File Manager to remove all files under the following directories if files exist:

DI/ D: INI

H:INI

\section{TFP 2:}

In GCSVI.VI window, verify that the archive path containes

W H: Set LOG INTERVAL SEC to 2 seconds.

\section{BTEP 3:}

In the GCSVI. VI window, push the PUSH TO SAVE button to toggle to the LOG TO FILE position.

\section{BTEP 4:}

simulate the HLAN problem. Disconnect "LABHOST" from "GCS1HOST" by breaking the HLAN connection at "GCS1HOST". To do this click the "Disconnect" button in File Manager. select the connection to the LABHosT computer "H: \\LABHOST\GCS1DATA".

\section{BTEP $5:$}

Under Program Manager set the GCS1HOST system date to the next day's date.

\section{BTHP 68}

Allow 3 minutes before proceeding.

\section{TEP 7:}

In File Manager verify that today's file "D: |NI|Y-MM-DDVI.RPT" was generated and that yesterday's file still remaines in the directory "D: WNI".

BTEP $8:$

In the GCSVI.VI window, push the LOG TO FILE button to toggle to the PUSH TO SAVE position. 


\section{ATFP $9:$}

U Under Program Manager set the GCS1HOST system date back to today's date.

\section{BWEP 108}

M Use the File Manager to remove all files under the directory "D: \NI".

\section{BTEP 118}

$M$ Use the File Manager to reconnect the network drive $\mathrm{H}$ :

"H: \\LABHOST\GCS1DATA".

\subsubsection{Ges Automatic calibration}

\section{TFP 1:}

$M$ In the discrete I/O drawer, verify that the LED $\$ 8$ on the circuit card is OFF. Terminals 17 and 18 control GC1 calibration gas solenoid valves sov- $* 20$ and sov- 21 .

U LED $\approx 8:$ OFF

BTAP $2:$

$M$ In the discrete I/O drawer, verify that the LED 19 on the circuit card is OFF. Terminals 19 and 20 control GC2 calibration gas solenoid valves sov- $* 30$ and sov- $* 31$.

\section{MJ LED *9: OFF}

M Use the File Manager to remove files listed if they exist:

MJ C: IGC1.CAL

M $\mathrm{C}: \mathrm{GC2}$. CAL

BTEP 4:

Under Program Manager record the current time of GCS1HOST system.

TIME: 10:4E:00 AM

\section{BTFP 58}

In the GCSVI.VI window, set and record front panel

calibration controls as follows:

GC1 NT- 20

CALIBRATION

TIME $=$ TIME FROM STEP $4+5$ MIN COMPUTED TIME $=10: 50: 00$ AM

DURATION $=5$ MIN

GC2 NT- -30

CALIBRATION

TIME = TIME FROM STEP $4+15$ MIN COMPUTED TIME $=10: 50: 00$ AM

DURATION $=5 \mathrm{MIN}$

NOTE: Read steps 6 through 13 before proceeding. Perform 
these steps in any order as applicable during the calibration process.

BWFe 68

Use the GCS1HOST system clock to record the actual time when GC1 and GC2 systems START their calibration process.

$$
\begin{aligned}
& \text { GC1 CALIBRATION START TIME: } \\
& \text { GC2 CALIBRATION START TIME: } \\
& \begin{array}{l}
10: 50: 02 \mathrm{AM} \\
\hline 10: 50: 02 \mathrm{AM}
\end{array}
\end{aligned}
$$

The expected results should be within (+-) 1 MIN of the computed times for GC1 and GC2 in step 5 .

\section{TFP 7:}

The front panel valve indicators will change color from yellow to red when the system starts the calibration process and remain red during calibration.

\section{TEP 8:}

M In the discrete $I / O$ arawer, verify that the LED $\# 8$ on the circuit card is oN during the GC1 calibration period.

Terminals 17 and 18 control GC1 calibration gas solenoid valves SOV $-\star 20$ and sov $-\star 21$.

$M$ LED $* 8:$ ON

\section{BTEP $9:$}

$M$ In the discrete I/O drawer, verify that the LED $* 9$ on the circuit card is oN during the GC2 calibration period. Terminals 19 and 20 control GC2 calibration gas solenoid valves SOV $-\star 30$ and SOV $-\star 31$.

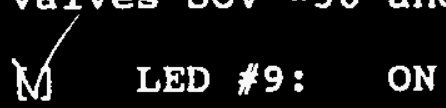

\section{TFP 108}

M Use the File Manager to verify the existence of files listed below during calibration period:

M. C: GC1.CAL

IJ C: IGC2.CAL

BTEP 11:

Use the GCS1HOST system clock to record the actual time when GC1 or GC2 system stops its calibration process.

GC1 CALIBRATION STOP TIME: 10:55:00 XU GC2 CALIBRATION STOP TIME: 10.55:00 AM

The expected results should be within (+-) 1 MIN of the computed time plus duration in step 5 .

\section{BTEP 12:}

In the discrete I/O drawer, verify that the LED $\# 8$ on the circuit card is OFF right after the termination of the GC1 
calibration process. Terminals 17 and 18 control GC1 calibration gas solenoid valves sov- $* 20$ and sov- 21 .

M LED *8: OFF

BTFP 13:

In the discrete I/O drawer, verify that the LED $* 9$ on the circuit card is OFF right after the termination of the GC2 calibration process. Terminals 19 and 20 control GC2 calibration gas solenoid valves sov $-\star 30$ and $\operatorname{sov}-\star 31$.

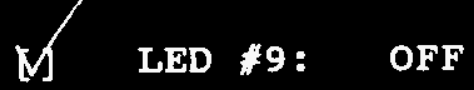

\section{BTEP $14:$}

$M$ Use the File Manager to verify that the following files do not exist after the calibration process is complete.

M C: 1 GC1.CAL

\section{BTEP 15:}

stop and close LabView GCSVI.VI application program.

\subsection{GC1 DATA BYBTEY}

\subsubsection{Test Preparation}

\section{BTEP $1:$} calibration operating mode per System Engineer's directions.

\section{TEP 2:}

Generate method file for GCl using certified standard calibration gas listed in TABLE 4.3.1.1 under the system engineer's direction and vendor instructions.

\section{STEP $3:$}

$M$ Record calibration values into TABLE 4.3.1.1

BTEP 4:

Save method file to C: MTI IEZChrom/200/methods/GC1.MTD.

\subsubsection{Vorify The Operation EzChrom 200 Data Byotom}

\section{BTEP 1:}

4 At the GC1 computer, use File Manager to remove all files under $\mathrm{C}: \mid \mathrm{GCl}$ directory.

BTER $2:$
Under the MTI programs group, start EZChrom 200.

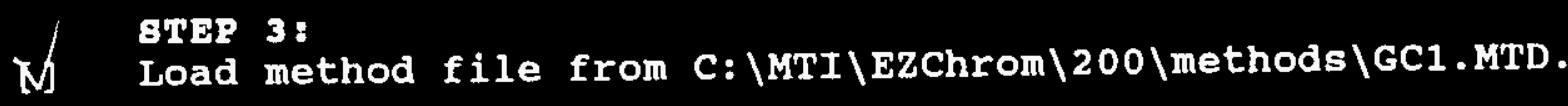


I Under REPORT menu, select the External standard for both channe $18 \mathrm{~A}$ and $\mathrm{B}$.

\section{BTEP 5:}

$M$ Select the sTART menu. A run window should appear. Set the following parameters and click on START to begin the sampling process.

Run ID

Number of Runs:(1-999, inf)

Time Between Injections: (secs)

[] Wait for External start

[X] Save [ ] Print

[X] DIF Save [ ] PRN Save [ ] Extended

User Program:

BTEP $6:$

LI Record the Amount 1 isted under the EXTERNAL STANDARD REPORT window into TABLE 4.3.1.2 for each run.

\section{BTEP 7:}

After five samples, use File Manager to examine the DIF file and record the concentration in TABLE 4.3.1.2. The DIF file is located at "C: $\mid G C 1 \backslash G C 1 . D I F "$.

\section{BTEP 8:}

If Under the Data and Analyze functions in EzChrom, load chromatograms and analyze all five samples. The chromatogram file name for each sample is GC1 and is followed by a sequential index number for extension. The index value corresponds to the sample number. (i.e. "D: |GCI $G C 1.3 "$ file is the 3rd chromatogram.)

BTEP $9:$

(14 Record the amount listed under EXTERNAL STANDARD Report window in TABLE 4.3.1.2 for each sample analyzed from the chromatogram in STEP 8 .

\section{BTFE 108}

Use File Manager to remove all the files under C: IGCl directory.

\subsubsection{Retrieve, Organize and Format Data Generated In BzChrom}

\section{BTEP 1:}

$M$ At GCS1HosT computer, use File Manager to remove all subdirectories and files under D:|GC1 directory.

\section{BTFP $2:$}

[V At GCS1HOST computer, run the GC1 data acquisition application program from the GCSAPPS group. 
[1 Press RUN button in the GC1 Data Acquisition Application window to START the data interface with EZChrom.

BHAP 38

IV Verify that the GC1.MTD method file is indicated at the bottom tool bar in Ezchrom.

\section{BTFP 4:}

(1) Select the START menu from Ezchrom. A run window should appear. Set the following parameters and click on START to begin sampling process.

Run ID

Number of Runs: (1-999, inf)

GC1

Time Between Injections:(secs) 120

[ ] Wait for External start

[X] Save

[ ] Print

[X] DIF Save [ ] PRN Save [ ] Extended

Usex Program:

BTPP 5:

[V Record the Amount listed under EXTERNAL STANDARD Report window into TABLE 4.3.3.1 for each run.

NOTE: A new directory for the day will be generated by GC1 application program. The directory naming convention is specified as $Y-M M-D D-G C 1$ where $Y-M M-D D$ refers to the year, month and day of today's date followed by GC1 for Gas Chromatograph 1 (i.e. 60211GC1 stands for the Feb 11, 1996 directory). All files under the directory also use the same naming convention with two different extensions. The extension .RPT is for the report file (1.e. 60211GC1.RPT) and the . F\# extension is the index number for the chromatogram (i.e. $60211 \mathrm{GC} 1.020$ is the 20th chromatogram).

\section{BTEP $6:$}

(1) Wait until EZChrom stops to proceed with the next step (i.e. after completion of 5 gas samples).

\section{BTPP 78}

In GCS1HOST computer, use File Manager to examine and record the formatted file names for the directory, report file, and chromatogram files under "D: /GC1" directory.

Directory name: $60228 \quad 87032 / 28 / 96$

Report file name: 622864 GC1 Chromatogram 001: Chromatogram 002 : 60228 GC1.RPT 6.0228 GC1.001 Chromatogram 003 : Chromatogram 004: 600228 CC1.002 60228 GC1.003

Chromatogram 005: $\frac{60228}{6028}$ GC1.005 
84FP 88

[1] Use the text editor to view the report file

"D: |GC1 IYMMDDGC1 \YMMDDGC1.RPT" where Y-MM-DD refers to the year, month and day of today's date.

\section{TEP 98}

[V Record the concentrations into TABLE 4.3.3.1 from the report file "D: |GC1/YMMDDGC1 \YMMDDGC1.RPT".

\section{BTEP 108}

[v] Verify and record the header contents in the report file "D: |GC1 \YMMDDGC1/YMMDDGC1.RPT". Check mark for each element that match to the contents in the TABLE 4.3.3.2.

\subsubsection{Append Data After Restart And Day Change verifications}

BTFP 18

From the report file "D:/GC1/YMMDDGC1/YMMDDGC1.RPT", verify and record the initial INDEX and TIME of the record number 5 into TABLE 4.3.4.1.

\section{BTFP 2:}

[y Under Program Manager set the time on both GCS1HOST and GC1 systems to 23:45 to simulate the rollover time (i.e. day change is at 24:00).

ATEP $3:$

(1) Use the GCS1HosT system clock window to monitor the date and time during the rollover process.

BTEP 4:

At GCS1HOST computer, press the RUN button in the GC1 Data Acquisition Application window to RE-START the data interface with EzChrom.

\section{TEP 5:}

[V At GC1 computer, select the START menu from EZChrom. A run window should appear. Set the following parameters and then click on START to begin the sampling process.

Run ID

GC1

Number of Runs:(1-999, inf) inf

Time Between Injections:(secs) 120

[ ] Wait for External start

[X] Save [ ] Print

[X] DIF Save [ ] PRN Save [ ] Extended

User Program:

BTFP $6:$

If Monitor the cCs1Hosi system clock window until the date changes to the next day and the time is 12:10 AM. Record the following parameters: 
Actual Date: $\frac{2-28-96}{2-29-96}$
Roll over Date:
Time:

M Pres 7: 7 ke key to terminate the EzChrom sampling process at GC1 computer.

[VTEP $8:$

Under Program Manager reset the current date and time on both the GCS1HOST and GC1 systems to the actual date and time.

\section{BTFP $9:$}

(1) At the GCS1HOST computer, use the text editor to view the report file "D:|GC1 \YMMDDGC1 \YMMDDGC1.RPT" where Y-MIY-DD refers to the year, month and day of today's date.

STEP $10:$

From the report file "D:/GC1/YMMDDGC1/YMMDDCC1.RPT", verify and record the INDEX and TIME of the appended record number 6 into TABLE 4.3.4.1.

\section{BTEP 118}

Use File Manager to verify and record the existence of the simulated directory for the next day, the report file, and all the chromatogram files.

Directory name:

Report file name: Chromatogram 001: Chromatogram 002: Chromatogram 003: Chromatogram 004: Chromatogram 005: Chromatogram 006: Chromatogram 007 : Chromatogram 008 :

\begin{tabular}{|c|c|}
\hline & \\
\hline$\frac{60229}{60229}$ & $\begin{array}{l}\text { RPT } \\
001\end{array}$ \\
\hline 60224 & \\
\hline 60225 & 03 \\
\hline 60224 & 004 \\
\hline 60229 & 0 \\
\hline & 006 \\
\hline$N$ & $\mathbf{G O}$ \\
\hline
\end{tabular}

(if applicable)

(if applicable)

(if applicable)

NOTE: The total chromatograms is depended on the time of termination of EZChrom sampling process.

\section{TFP 12:}

Use File Manager to remove all subdirectories and files under D: IGC1 directory.

\section{GTEP $13:$}

[V Press QUIT button on the GC1 Data Acquisition Application.
4.3 .5
Calibration an VI and GC1 Data noguiaition Application

\section{TFE 1:}


and close all windows under Program Manager.

\section{BTEP $2:$}

[1] Start LabView program by selecting "GCSVI" icon from GcsApPs group.

STEP 3:

(1) The GCSVI.VI front panel should now be displayed on the GCS1HOST computer.

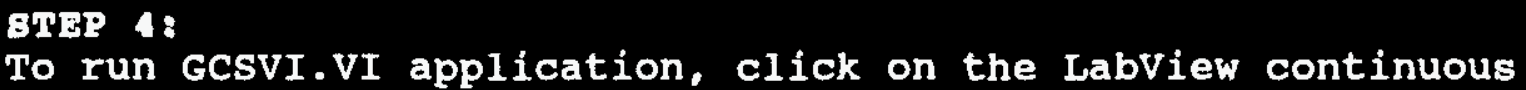
run icon.

BTEP 5:
Set front panel controls as follows:

FILE CONFIGURATION:

* ARCHIVE PATH: H:INI (DEFAULT)

* LOG INTERVAL SEC: 60

* RECORD DATA: PUSH TO SAVE

(DEFAULT)

GC1 NT-20

CALIBRATION

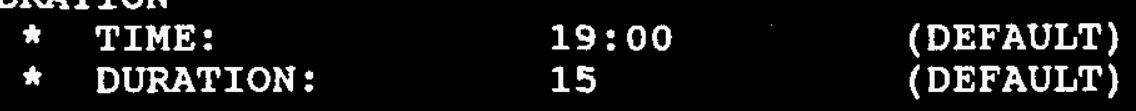

GC2 NT-30

CALIBRATION

$\begin{array}{lll}* & 20: 00 & \text { (DEFAULT) } \\ \text { * DUME: } & 15 & \text { (DEFAULT) }\end{array}$

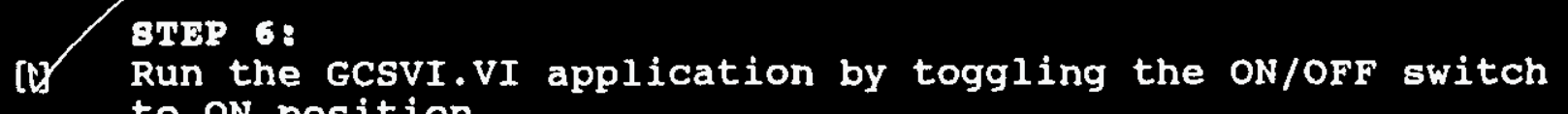
to oN position.

UTEP 7: during the calibration process.

[y ATEP 8: application program from the GCSAPPS group.

1. Press the RUN button in the GC1 Data Acquisition Application window to START the data interface with EZChrom.

\section{TFP 98}

At GC1 computer, select the START menu from Ezchrom. A run window should appear. Set the following parameters and click on START to begin sampling process.

Run ID

Number of Runs: $(1-999$, inf $)$

GC1

inf 
Time Between Injections: (secs)

120

[ ] Wait for External start

[X] Save [] Print

[X] DIF Save [] PRN Save [ ] Extended

User Program:

\section{BTEP 108}

Record the current time of GCS1HOST system clock.

TIME:

13:49:30

\section{BTSP 118}

[y In the GCSVI.VI window, set and record front panel calibration controls as follows:

GC1 NT $-\mathbf{- 2 0}$

CALIBRATION

TIME $=$ TIME FROM STEP $10+6$ MIN DURATION $=10 \mathrm{MIN}$

\section{THE $12:$}

Verify that the GCSVI.VI application is reading the actual concentrations shown in Ezchrom system. Compare and record the GC1 NT-20 display of GCSVI.VI application and the EZChrom display for H2-LO PPM and H2-HI PPM.

\begin{tabular}{|c|c|c|c|}
\hline \multicolumn{2}{|c|}{$\begin{array}{c}\text { GCSVI.VI Application } \\
\text { GC1 NT-20 }\end{array}$} & \multicolumn{2}{|c|}{$\begin{array}{c}\text { EZChrom } \\
\text { GC1 }\end{array}$} \\
\hline H2-LO PPM & H2-HI PPM & H2-LO & H2-HI \\
\hline 100 & 100 & 99.779 & 99.938 \\
\hline
\end{tabular}

\section{Grip 13:}

Wait until the time indicated on the GCS1HosT system clock reaches the time from step $10+22$ MIN then prosees-with the next step.

\section{BTEE 148} proceed $2 / 28 / 96$

Q Press Esc key to stop the EZChrom sampling process at GC1 computer.

BTHP $15:$

(d) Stop and close LabView GCSVI.VI application program.

8TEP 16:

1. In GCS1HOST computer, use the text editor to view the report - file "D: /CC1/YMMDDGC1 \YMMDDGC1.RPT" where Y-MM-DD refers to the year, month and day of today's date.

NOTE: The calibrated records in the report file are identified with a 1 under Cal column. A 0 was 
used to identify normal sample records.

BTEP 17:

From the report file "D:/GC1/YMMDDGC1/YMMDDGC1.RPT", record the time when the calibration starts and the time when the calibration ends.

1. CAL START TIME: $\frac{12: 55}{14: 03}$
\[ \text { CAL END TIME: } \]
$\frac{14 \text { CAL START TIME }}{8}$

\section{BTEP $18:$}

(1) The calibration time setting from step 11 and the reading from step 17 should be within (t-) 4 MIN of each other.

\section{THP 19:}

d Use File Manager to remove all subdirectories and files under D: \GC1 directory.

8THP 20:
Press QUTT button on the GC1 Data Acquisition Application.

BTEP 218

16 At the GCS1HOST computer, terminate all active applications and close all windows under Program Manager.

\subsubsection{Compress And Trangfer ce1 Data Across ahny}

The following series of steps are designed to verify the reduction of the data files and data tranfer functions in the software. The test data set was created and stored in the directory "D: ITHST GCI" prior to the test. The test data set contains the report fille "60208GC1.RPT" and all the associated chromatograms. The report file contains the calibration records, the zero concentration records.

\section{BTPP 1:}

In the File Manager verify that the report and all the associated chromatogram files exist in the testing directory "D:|TST. GC1\60208GC1".

BTEP 2:

4) Use File Manager to verify the "H:\GCI\60208GC1.zIP" and the "H: IGC1\60208GC1.RPT" files do not exist.

\section{BTFP 3:}

by Use File Manager to copy the subdirectory and all files under "D:ITST.GC1" into the directory "D: IGC1".

\section{QTEP 1:}

N Use tejt editor to examine and verify the parameters in "C:|BIN|ZIP1.INI" file. If any of the parameters in the

$$
\begin{aligned}
& \text { GCH_zip Tux Ples } \\
& \text { cVV } \\
& 2 / 28 / 96
\end{aligned}
$$


ses $2 / 2 r / 96$
$6 C 1-210.5 N T$ cuv $2 / 28 / 96$

UHC-SD-WH-ATR-172

Rev. 0

Page 32

ZIP1-INf file do not match the parameters listed below, correct them and save the corrected parameters back to "C: \BIN|RIA1-XIF" file.

$$
G C 1-2, P . I N I \text {, Tas } 2 / 28 / 46
$$

$M$, path $=$ c: $\mid$ bin $\backslash$ pkzip.exe $2 / 28 / 96$

M ippath $=\mathrm{d}:|\mathrm{gc} 1|$

I. out_path $=h:|g c 1|$

I nth_c $=2$

NOTE: Ignore all parameter definitions in the c: $\backslash$ BIN tzIP1 INI file. $G C I-Z I P$. INI ger $2 / 2 \% / 6$

BTFP 58 $2 \times+2 / 28 / 96$

Verify that the contents of the report file

"D:|GC1|60208GC1 \60208GC1.RPT and TABLE 4.3.6.1 are the same.

\section{BTEP 6:}

$[\gamma$ Under Program Manager set the date on the GCs1HosT system to 02-09-1996.

\section{BTEP 7:}

In File Manager, ensure that all directories are closed before starting the compress and transfer process.

Run the C:|BIN|GC1ZIP. EXE program.

8TEP $8:$

Use File Manager to verify that the files

"H: /GC1 160208GC1.ZIP" and "H:|GC1\60208GC1.RPT" exist.

\section{BTEP 9:}

Use file Manager to verify that the "D: \GC1\60208GC1" directory was removed.

\section{STFP $10:$}

Run Winzip to open and view the "H:|GC1/60208GC1.zIP" file without unzipping.

BTEP 118

$\checkmark$ The calibration records, the zero concentration records, and every other chromatograms are preserved in the file

"H: IGC1\60208GC1.zIP". Verify this in TABLE 4.3.6.1 by entering an $S$ or a $U$ for saved or unsaved chromatograms in the column labelled actual results.

$$
\text { GC1 gur 2/28/ir }
$$

\section{BTPR $12:$}

GTEP 12: GC1 CVU $2 / 28 / 96$
Use File Manager to remove the "H: JCC $760208 G C 1.2 I P "$ and the "H: \GC1 60208 GC1.RPT" files.

\section{TaP 13:}

Under Program Manager set the date on the GCS1HOST system back to the current date. 


\section{3 .7 \\ Data Handing Capablitties During Notwork Outagas}

8HEP 1:

[u At the GC1 computer, use File Manager to remove all files under the $c: \mid G C 1$ directory only if they exist.

\section{BTEP 2:}

A At the GCS1HOST computer, terminate all active applications and close all windows under Program Manager.

BTPP 3:

[1 Use File Manager to remove all subdirectories and files under the D:IGCl directory only if they exist.

BTEP 4:

[1 Run the GC1 Data Acquisition Application program from the GCSAPPS group.

[Y Press RUN button in the GC1 Data Acquisition Application window to START the data interface with EZChrom.

\section{TEP 5:}

af At the GC1 computer, verify that the method file "GC1.MTD" is indicated at the bottom tool bar in EZChrom.

\section{TPP 6:}

select the START menu from EZChrom. A run window should appear. Set the following parameters and click on START to begin the sampling process.

Run ID GC1

Number of Runs:(1-999, inf) inf Time Between Injections:(secs) 120

[ ] Wait for External start [X] Save [ ] Print

[X] DIF Save [ ] PRN Save [ ] Extended User Program:

\section{BTEP 7:}

[V Monitor the GC1 Data Acquisition Application window. Wait until the message "Finished Appending $" 5$ " appears in this window to proceed with the next step.

\section{BTEP $8:$}

[V To simulate the local network problem, disconnect "GC1" from "GCS1HOST" by breaking the local network connection at "GCS1HOST". To do this click on the "Disconnect" button in File Manager. Select the connection to the GC1 computer "F: ||GC1\GC1".

8THP $9:$

[1 Verify that the GCS1HOST system is not locked up. 
8TEP 108

a) At GC1 computer, wait until EzChrom has finished taking four or five more samples. Press Esc key to terminate the sampling process.

[1 Use File Managex to verify that GC1.DIF and the chromatogram files are stored locally at the GC1 computer under "C:|GC1" directory.

BMEP 128

[0 Use File Manager to remove all files under c:lGC1 directory.

\section{BTEP 138}

[1) Use the File Manager to reconnect the network drive $F$ "F: \|GC1\GC1".

\section{BTEP 14:}

[V To simulate the HLAN network outage, disconnect "LABHOST" from "GCS1HosT" by breaking the HLAN network connection at GCS1HOST. To do this click on the "disconnect" button in File Manager. Select the connection to the LABHOsT computer "H: \\LABHOST\GCS1DATA".

\section{TEP 15:}

WJ Using File Manager verify that the report and the chromatogram files exist in today's directory

"D: \GC1 \YMMDDGC1".

\section{BTFP 168}

LX Under Program Manager set the date on GCS1HosT to the next day's date.

\section{TEP $17:$}

41 To start the compress and transfer process, run C: \BIN\GC1ZIP. EXE program.

\section{BTEP $18:$}

Use the File Manager to verify that "D: IYMMDDGC1.zIP" exists and then delete it.

\section{TEP $19:$}

CJ Use file Manager to verify that the directory

"D: IGC1/YMMDDGC1" was removed.

\section{BTEP 20 :}

Under Program Manager reset the date on GCS1HOST back to today's date.

\section{BTEP 21:}

C] Use the File Manager to reconnect the network drive $H$ "H: \ILABHOST\GCSIDATA". 


\section{STPP $22:$}

[V Terminate al1 active applications and close all program groups in GCS1HOST and GC1 computex.

\subsection{GC2 DATA BYBTEY}

\subsubsection{Test Preparation}

\section{BTEP 18}

[1 Place the gas delivery system and GC2 instrument into their calibration operating mode per System Engineer's airections.

\section{BT2P $2:$}

[1] Generate method file for GC2 using certified standard calibration gas listed in TABLE 4.4.1.1 under the system engineer's direction and vendor instructions.

- BTEP 3:

[1 Record calibration values into TABLE 4.4 .1 .1

1) STEP 4:

\subsubsection{Verify The Operation Ezchrom 200 Data Byatem}

\section{BTEP 1:}

M At the GC2 computer, use File Manager to remove all files under $\mathrm{C}$ : IGC2 directory.

\section{BTEP 2 :}

M Under the MTI programs group, start EZChrom 200.

\section{BTFP $3:$}

W Load method file from $C: \backslash M T I \backslash E Z C h r o m \backslash 200 \backslash$ methods $\backslash G C 2 . M T D$.

\section{BTEP 4:}

[V Under REPORT menu, select the External standard for both channels $A$ and $B$.

\section{TFP $5:$}

(1) Select the START menu. A run window should appear. Set the following parameters and click on START to begin the sampling process.

Run ID GC2

Number of Runs: (1-999,inf) 5 Time Between Injections:(secs) 120 [ ] Wait for External start [X] Save [ ] Print [X] DIF Save [ ] PRN Save [ ] Extended User Program: 
STEP $6:$

Record the Amount listed under the EXTERNAL STANDARD REPORT window into TABLE 4.4.1.2 for each run.

(1) After five samples, use File Manager to examine the DIF file and record the concentration in TABLE 4.4.1.2. The DIF file is located at "C: /GC2 \GC2.DIF".

BSTP $8:$

$M$ Under the Data and Analyze functions in EzChrom, load chromatograms and analyze all five samples. The chromatogram file name for each sample is GC2 and is followed by a sequential index number for extension. The index value corresponds to the sample number. (i.e. "D: |GC2 GGC2.3" file is the 3rd chromatogram.)

BTFP $9:$

Record the amount 1 isted under EXTERNAL STANDARD Report window in TABLE 4.4.1.2 for each sample analyzed from the chromatogram in STEP 8 .

\section{BTFP $10:$}

$M$ Use File Manager to remove all the files under $C:$ IGC2 directory.

\subsubsection{Retrieve, Organize and rormat Data Generated In Ezchrom}

\section{TEP 1:}

$M$ At GCS1HOST computer, use File Manager to remove all subdirectories and files under D: IGC2 directory.

\section{BTEP $2:$} application program from the GCSAPPS group. press RUN button in the GC2 Data Acquisition Application window to START the data interface with EZChrom.

\section{BTEP 3:}

Ut STEP 4: appear. Set the following parameters and click on START to begin sampling process.

Run ID

Number of Runs:(1-999, inf)

Time Between Injections: (secs) 120

[] Wait for External start

[X] Save [ ] Print

[X] DIF Save [ ] PRN Save [ ] Extended

User Program:

GC2

5 


\section{BTEP $5:$}

M) Record the Amount listed under EXTERNAL STANDARD Report window into TABLES 4.4.3.1 for each run.

NOTE: A new directory for the day will be generated by GC2 application program. The directory naming convention is specified as $Y-M M-D D-G C 2$ where $Y-M M-D D$ refers to the year, month and day of today's date followed by GC2 for Gas Chromatograph 2 (i.e. $602116 C 2$ stands for the Feb 11, 1996 directory). All files under the directory also use the same naming convention with two different extensions. The extension .RPT is for the report file (i.e. 60211GC2.RPT) and the . * * extension is the index number for the chromatogram (i.e. $602116 C 2.020$ is the 20th chromatogram).

\section{STPP $6:$}

Wait until EzChrom stops to proceed with the next step (i.e. after completion of 5 gas samples).

\section{BTFP 7:}

In GCS1HOST computer, use File Managex to examine and record the formatted file names for the directory, report file, and chromatogram files under "D: |GC2" directory.

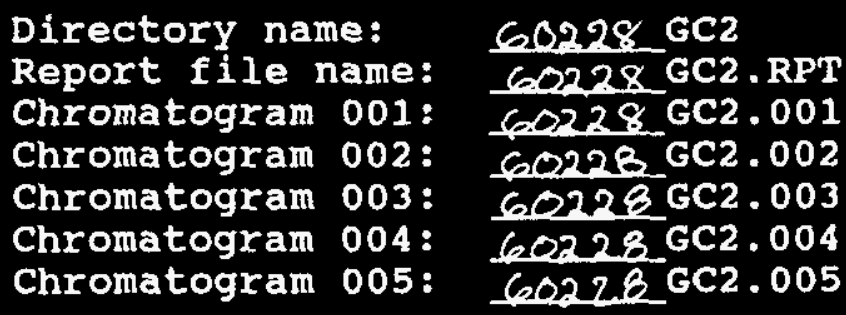

\section{BTEP 8:}

Use the text editor to view the report file

"D: IGC2 \YMMDDGC2 \YMMDDGC2. RPT" where Y-MM-DD refers to the year, month and day of today's date.

\section{BTEP 9 :}

M Record the concentration into TABLES 4.4.3.1 from the report file "D: /GC2 \YMMDDGC2 \YMMDDGC2 . RPT" .

\section{BTFP $10:$}

Verify and record the header contents in the report file "D: |GC2 \YMMDDGC2 \YMMDDGC2.RPT". Check mark for each element that match to the contents in the TABLE 4.4.3.2. 


\subsubsection{Append Data After Restart And Day Change Verifleations}

\section{BTEP 18}

From the report file "D: /GC2 IYMMDDGC2 IYMMDDGC2.RPT", verify and record the initial INDEX and TIME of the record number 5 into TABLE 4.4.4.1.

\section{STAP $2:$}

Under Program Manager set the time on both GCS1HOST and GC1 systems to 23:45 to simulate the rollover time (i.e. day change is at 24:00).

BTBP $3:$

UJ Use the GCS1HOST system clock window to monitor the date and time during the rollover process.

ATDP A:

At GCS1HOST computer, press the RUN button in the GC2 Data Acquisition Application window to RE-START the data interface with EZChrom.

\section{BTwP 5 :}

At GC2 computer, select the START menu from Ezchrom. A run window should appear. Set the following parameters and then click on START to begin the sampling process.

Run ID

Number of Runs: (1-999, inf)

Time Between Injections:(secs)

[ ] Wait for External start

[X] Save [ ] Print

[X] DIF Save [ ] PRN Save [ ] Extended

User Program:

BTEP 6:

Monitor the GCS1HosT system clock window until the date changes to the next day and the time is 12:10 AM. Record the following parameters:

Actual Date: Rollover Date: Time:

$$
\frac{\frac{2-28-96}{2-29-96}}{1210 \mathrm{Am}}
$$

BTEP 7: Press Esc key to terminate the EZChrom sampling process at GC2 computer.

BTEP 8:

Under Program Manager reset the current date and time on both the GCS1HOST and GC2 systems to the actual date and time. 


\section{BTEP $9:$}

At the GCS1HOST computer, use the text editor to view the report file "D:/GC2 /YMMDDGC2 /YMMDDGC2.RPT" where Y-MM-DD refers to the year, month and day of today's date.

8TEP $10:$

[v From the report file "D:|GC2/YMMDDGC2/YMMDDGC2.RPT", verify and record the INDEX and TIME of the appended record number 6 into TABLE 4.4.4.1.

\section{TF尺 $11:$}

Use File Manager to verify and record the existence of the simulated directory for the next day, the report file, and all the chromatogram files.

Directory name:

Report file name:

Chromatogram 001:

Chromatogram 002:

Chromatogram 003:

Chromatogram 004:

Chromatogram 005:

Chromatogram 006:

Chromatogram 007:

Chromatogram 008 :

\begin{tabular}{|c|c|}
\hline 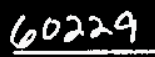 & GC \\
\hline 4 & $\mathrm{GC}_{2}$ \\
\hline & \\
\hline & GC \\
\hline 29 & GC \\
\hline 100229 & GC \\
\hline & $\mathbf{G C}$ \\
\hline$N / 2$ & $\mathrm{ec}$ \\
\hline & \\
\hline & GC \\
\hline
\end{tabular}

(if applicable)

(if applicable)

(if applicable)

NOTE: The total number of chromatograms depends on the time of termination of Ezchrom sampling process.

8TFP 12:

$\sqrt{1}$

Use File Manager to remove all subdirectories and files under D: \GC2 directory.

BTEP $13:$

$\sqrt{ }$ Press QUIT button on the GC2 Data Acquisition Application.

4.4.5 Calibration and Display Interface Between Iabview VI and ec2 Data Aoquisition Application

14) At the GCS1HOST computer, terminate all active applications and close all windows under Program Manager.

BTEP 2:

1 start Labview program by selecting "GCSVI" icon from GCSAPPS group.

BTEP 3 :

V The GCSVI.VI front panel should now be displayed on the GCS1HOST computer. 
BTEP 4:

$\checkmark$ To run GCSVI.VI application, click on the LabView continuous run icon.

1) Set front panel controls as follows:

FILE CONFIGURATION:

$\begin{array}{llll}* & \text { ARCHIVE PATH: } & \text { H: NNI } & \text { (DEFAULT) } \\ \text { * LOG INTERVAL SEC: } 60 & \text { (DEFAULT) } \\ * & \text { RECORD DATA: } & \text { PUSH TO SAVE } & \end{array}$

GC1 NT-20

CALIBRATION

* TIME: $\quad 19: 00$

(DEFAULT)

* DURATION :

15

(DEFAULT)

GC2 NT-30

CALIBRATION

* TIME: 20:00 (DEFAULT)

* DURATION: 15 (DEFAULT)

BISEP 6:

Run the GCSVI.VI application by toggling the ON/OFF switch to oN position.

BTPP 7:

Use the GCS1HOST system clock window to monitor the time during the calibration process.

\section{BTEP 8:}

At GCS1HOST computer, run the GC2 data acquisition

application program from the GCSAPPS group.

Press the RUN button in the GC2 Data Acquisition Application window to START the data interface with EZChrom.

\section{BTEP 9:}

At GC2 computer, select the START menu from EzChrom. A run window should appear. Set the following parameters and click on START to begin the sampling process.

Run ID

Number of Runs:(1-999, inf)

GC2

Time Between Injections:(secs) 120

[ ] Wait for External start

[X] Save [ ] Print

[X] DIF save [] PRN Save [ ] Extended

User Program:

BTEP 10:

Record the current time of GCS1HOST system clock.

TIME: $16: 50$ 


\section{2rig? 118}

In the GCSVI.VI window, set and record front panel calibration controls as follows:

GC2 $\mathrm{NT}-30$

CALIBRATION

TIME = TIME FROM STEP $10+6 \mathrm{MIN}$ COMPUTED TIME $=16.56$

DURATION $=10 \mathrm{MIN}$

\section{BTPD 128}

d Verify that the GCSVI.VI application is reading the actual concentrations shown in Ezchrom system. Compare and record the GC2 NT-30 display of GCSVI.VI application and the EZChrom display for CH4-LO, N2O-LO, CH4-HI and N2O-HI PPM.

\begin{tabular}{|c|c|c|c|c|c|c|c|}
\hline \multicolumn{4}{|c|}{$\begin{array}{c}\text { ecsvI.VI Application } \\
\text { ec2 N2=-30 }\end{array}$} & \multicolumn{4}{|c|}{$\begin{array}{l}\text { Ezchrom } \\
\text { ec2 }\end{array}$} \\
\hline $\begin{array}{c}\text { CH } 4 \\
\text { LO }\end{array}$ & $\begin{array}{l}\text { N2O } \\
\text { LO }\end{array}$ & $\begin{array}{c}\text { CH4 } \\
\text { HI }\end{array}$ & $\begin{array}{c}\text { N2O } \\
\text { HI }\end{array}$ & $\begin{array}{l}\text { CH4 } \\
\text { LO }\end{array}$ & $\begin{array}{l}\mathrm{N} 20 \\
\mathrm{LO}\end{array}$ & $\begin{array}{c}\text { CH4 } \\
\text { HI }\end{array}$ & $\begin{array}{c}\mathrm{N} 20 \\
\mathrm{HI}\end{array}$ \\
\hline 175 & 76 & 125 & $176^{\circ}$ & $17 \times 9$ & 1725 & 174.8 & 175.5 \\
\hline
\end{tabular}

8TAP 13:

[1 Wait until the time indicated on the GCS1HOST system clock reaches the time from step $10+22$ MIN then proceed with the next step.

\section{T5P 148}

Press Esc key to stop the EzChrom sampling process at GC2 computer.

\section{BTHP $15:$}

stop and close LabView GCSVI.VI application program.

\section{TEP 16:}

[] In GCS1HOST computer, use the text editor to view the report file "D: |GC2 \YMMDDGC2 \YMMDDGC2.RPT" where Y-MM-DD refers to the year, month and day of today's date.

NOTE: The calibrated records in the report file are identified with a 1 under Cal column. A 0 was used to identify normal sample records.

\section{STEP $27:$}

From the report file "D: /GC2 \YMMDDGC2 \YMMDDGC2 :RPT", record the time when the calibration starts and the time when the calibration ends.

[U CAL START TIME:

$\checkmark$ CAL END TIME:

G) DURATION $=$

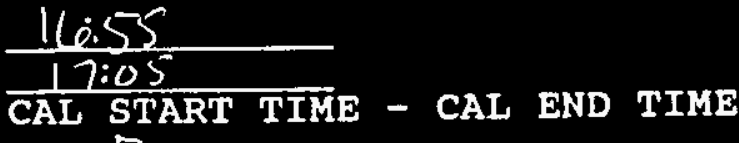


GTEP 188

The calibration time setting from step 11 and the reading from step 17 should be within (+-) 4 MIN of each other.

\section{BLEP $19:$}

Use File Manager to remove all subdirectories and files under D: $\mid \mathrm{GC} 2$ directory.

\section{BTED 208}

Press QUIT button on the GC2 Data Acquisition Application.

\section{TEP 218}

(J) At the GCS1HOST computer, terminate all active applications and close all windows under Program Manager.

\subsubsection{Compress and Transfer ce2 Data Acroas IMAN}

The following series of steps are designed to verify the reduction of the data files and data tranfer functions in the software. The test data set was created and stored in the directory "D: ITEST.GC2" prior to the test. The test data set contains the reportusile "60208GC2.RPT" and all the associated chromatograms. The report file contains the calibration records, the zero concentration records.

\section{BTEP 18}

4 In the File Manager verify that the report and all the associated chromatogram files exist in the testing directory "D: \TST.GC2\60208GC2".

\section{BTEP $2:$}

$y$

Use File Manager to verify the "H: |GC2\60208GC2.ZIP" and the "H: |GC2 $160208 G C 2$.RPT" files do not exist.

\section{BTEP $3:$}

Use File Manager to copy the subdirectory and all files under "D: ITST.GC2" into the directory "D: IGC2".

$$
\text { 4is } 2-2 r-96
$$

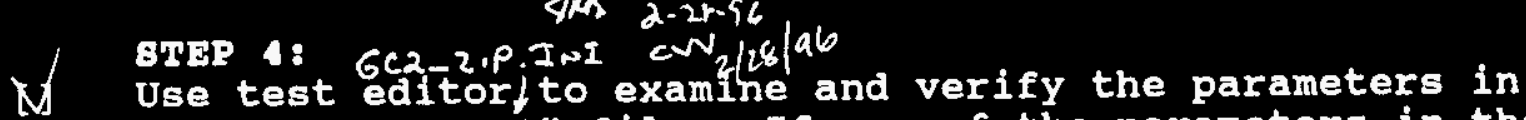
"C: |BIN\ZIR2. INI" file. If any of the parameters in the ZIP2. INI file do not match the parameters 1 isted below, correct them and save the corrected parameters back to "C: \BIN\ZIP2-INI" file.

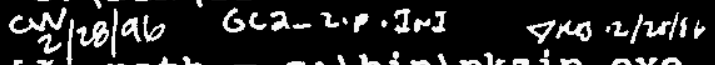

$$
\begin{aligned}
& \text { [ } \int^{2} \text { path }=c: \mid b i n \backslash p k z i p . e x e \\
& \text { J } \mathrm{zippath}=\mathbf{d}:|g c 2| \\
& \text { IJ out_path }=\mathrm{h}:|g c 2| \\
& \text { L) } n t_{-}-\mathrm{c}=2
\end{aligned}
$$

NOTE: Ignore all parameter definitions in the C:IBIN|ZIP2-IHI file.

$$
\begin{aligned}
\text { GC2-2P. Ins } & \text { QRe 2/28/46 } \\
& \operatorname{CUN} 2 / 28 / 96
\end{aligned}
$$


STFE 5:

Verify that the contents of the report file

"D: \GC2 $\backslash 60208 G C 2 \backslash 60208 G C 2$.RPT and TABLE 4.4.6.1 are the same.

BTEP $6:$

Under Program Manager set the date on the GCS1HOST system to 02-09-1996.

\section{TSP 78}

In File Manager, ensure that all directories are closed before starting the compression and transfer process.

Run the C: IBINIGC2ZIP. EXE program.

\section{TEP $8:$}

Use File Manager to verify that the files

"H: \GC2 \60208GC2 .ZIP" and "H:|GC2\60208GC2.RPT" exist.

\section{BTHP $9:$}

Use file Manager to verify that the "D: \GC2\60208GC2"

directory was removed.

\section{BTEP $10:$}

1) Run winzip to open and view the "H: /GC2\60208GC2.zIP" file without unzipping.

BTPR 118

(1) The calibration records, the zero concentration records, and every other chromatograms are preserved in the file "H: |GC2 $\backslash 60208 \mathrm{GC2}$, ZIP". Verify this in TABLE 4.4.6.1 by entering an $s$ or a $U$ for saved or unsaved chromatograms in the column labelled actual results.

\section{BTEP $12:$}

WJ Use File Manager to remove the "H:|GC|60208GC2.ZIP" and the "H: \GC2\60208GC2.RPT" files.

8TPP 138

¿ل Under Program Manager set the date on the GCS1HOST system back to the current date.

\subsubsection{Data Fandling Capabilitios During Network Outagea}

\section{STEP 18}

$M$ At the GC2 computer, use File Manager to remove all files under the C: $\mathrm{GC2}$ directory only if they exist.

\section{BTFP 2:}

At the GCS1HOST computer, terminate all active applications and close all windows under Program Manager.

ATHP 3 :

Use File Manager to remove all subdirectories and files 
under the D: IGC2 directory only if they exist.

BTDP 48

M Run the GC2 Data Acquisition Application program from the GCSAPPS group.

$M$ Press RUN button in the GC2 Data Acquisition Application window to START the data interface with EZChrom.

M ATHP 5: is indicated at the bottom tool bar in ezchrom.

\section{STIP 68}

Select the START menu from Ezchrom. A run window should appear. Set the following parameters and click on START to begin the sampling process.

Run ID

Number of Runs: (1-999, inf)

GC2

Time Between Injections:(secs) 120

[] Wait for External start

[X] Save [ ] Print

[X] DIF Save [, PRN Save [ ] Extended

User Program:

\section{BISP $7:$}

Monitor the GC2 Data Acquisition Application window. Wait until the message "Finished Appending " $^{\prime \prime}$ appears in this window to proceed with the next step.

\section{BTEP 88}

To simulate the local network problem, disconnect "GC2" from "GCSIHOST" by breaking the local network connection at "GCS1HOST". To do this click on the "Disconnect" button in File Manager. Select the connection to the GC̣ computer "G: $\mid \backslash G C 2 \backslash G C 2 "$.

BrEP 9:

Verify that the GCS1HOST system is not locked up.

At GC2 computer, wait until EZChrom has finished taking four or five more samples. Press Esc key to terminate the sampling process.

\section{T5P 11:}

Use File Manager to verify that GC2.DIF and the chromatogram files are stored locally at the GC2 computer under "C: IGC2" directory.

\section{BTEP $12:$}

Use File Manager to remove all files under $c: 16 C 2$ directory. 
8TEP $13:$

Use the File Manager to reconnect the network drive $G$ "G: ||GC2 $\mid$ GC2".

\section{BTEP 148}

To simulate the HLAN network outage, disconnect "LABHOST" from "GCS1HOST" by breaking the HLAN network connection at GCS1HOST. To do this click on the "disconnect" button in File Manager. Select the connection to the LABHOST computer "H: \\LABHOST\GCS1DATA".

\section{BTEP 15:}

Using File Manager verify that the report and the chromatogram files exist in today's directory

"D: |GC2 \YMMDDGC2".

BTEP 16:

Under Program Manager set the date on GCS1HOST to the next day's date.

\section{BTEP 17:}

To start the compress and transfer process, run

C: \BIN\GC2ZIP. EXE program.

\section{BTFP 188}

Use the File Manager to verify that "D:|YMMDDGC2.ZIP" exists and then delete it.

\section{BTEP 198}

Use file Manager to verify that the directory

"D: \GC2 \YMMDDGC2" was removed.

\section{BTEP $20:$}

Under Program Manager reset the date on GCS1HOST back to today's date.

\section{TBP 218}

Use the File Manager to reconnect the network drive $H$ "H: \\LABHOST \GCS1DATA".

\section{BTEP $22:$}

Terminate all active applications and close all program groups in GCS1HOST and GC2 computer.

\section{TFP $23:$}

Turn OFF the system sample pump per the System Engineer's instruction. 


\subsection{FTIR DATA BYBTFY}

\subsubsection{Tost Preparation}

\section{BTEP 1:}

At the GCS1HOST computer, use File Manager to remove all subdirectories and files under the directory "D: IFTIR" if they exist.

\section{BTEP 2:}

At the FTIR computer, verify that the directory "C: IFTIR" contains no files. If any files exists, use file Manager to remove them.

\section{BTEP $3:$}

Use File Manager to verify that the FTIR computer contained the following configuration files:

UJ

C: $\mid W I N$ IR $\backslash$ CONF $\backslash$ CONF001.FTS

$C: \mid W I N-I R \backslash$ CONF $\backslash$ BACK 125 . SPC

C: $|W I N-I R|$ CONF $\backslash N H 3$ RED. $Q$

\section{TFP 4:}

Use the Text Editor to verify that the FTIR computer file "C: |WIN-IR/CONF\PARAM. INP" containes the following parameters:

c: |win_ir|conf|

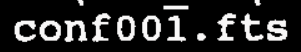
back_125.spc nh3 3 red.q

2

\subsubsection{Normal Yode Test}

\section{BTEP 18}

start the "Win-IR" application by clicking the icon located under the win-IR program group.

\section{BTEP $2:$}

Enter the "Collect" menu and select "Advanced Scan Menu" to load and modify the FTs configuration file

"C: \Win_IR\conf\conf001.FTS".

\section{T푸 $3:$}

Set the Number of Scans to 8 . Save the FTS configuration file to "C:|Win_IR/conf/conf001.FTs" and return to the BioRad Win-IR screen.

\section{STEP $4:$}

start the FTIR program by clicking on the SPFTIRII button. 
STEP 5:

Once scanning starts, check the lower left hand corner of the screen for the file name. The file name "X-MM-DD-\#\#" refers to the year "Y", month "MM", day "DD" and the interferogram index number " $* * ; "$ ". It should match today's date and start with the index number 001 for the first sample.

\section{BTFP $6:$}

Wait until the index number of the last 3 digits in the file name located at the lower left corner of Win-IR screen indicates 009 and proceed prompthly with the next step.

\section{T28 7:}

During a scan, depress the Escape key, to stop the scaning process.

\section{TEP 8:}

Copy the index number of the last 3 digits in the file name located at the lower left corner of win-IR screen.

RUN ID: 009

\section{TEP 9:}

Y

In GCSiHosT computer, use File Manager to verify that the subdirectory "D:|FTIR/YMMDDIR" has been created and is titled with today's date followed by an "IR".

\section{BTFP 10:}

Use File Manager to view and record the formated file names in the directory "D:|FTIR|YMMDDIR". The YMMDD \#\#\#. SPC interferogram file numbers will be alternate even numbers ( i.e. YMMDD002.SPC, YMMDD004.SPC, YMMDD006.SPC, ......).

Directory name: $\quad 60228$ IR

Report file name: 60228 IR.RPT

Interferogram 002: 60228002.SPC

Interferogram 004: 60228004.SPC

Interferogram 006: 60228006. SPC

Interferogram 008: 60228008 . SPC

Interferogram 010:

N/a SPC

\section{(if applicable)}

\section{TFP 118}

$\checkmark$ Use the Text Editor to view the report file

"D: |FTIR\YMMDDIR/YMMDDIR.RPT" where Y-MM-DD refers to the year, month and day of today's date.

\section{BTEP 12:}

IJ Verify that the header contents in the report file "D: |FTIR YYMDDIR/YMMDDIR.RPT" match the items below:

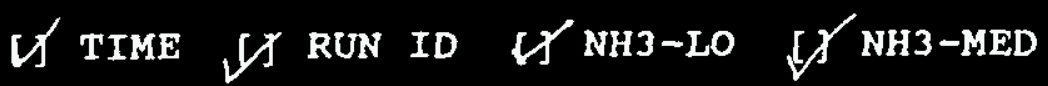


BTEP 138

Verify that every calculated concentration record is present (i.e. RUN ID: 001, 002, 003...).

\t records are sequentially numbered

BTEP 148

Verify that records are time stamp.

4.5.3 Interrupted Hode Test

Brme 1:

K

At GCSiHosT computer, use File Manager to view and record the RUN ID number of the last record in the report file "D \FTIR \YMMDDIR \YMMDDIR.RPT".

RUN ID: 008

\section{BTEP $2:$}

$\sqrt{y}$

Assure at least 5 minutes have elapsed since the Win-IR

program was stopped at section 4.5 .2 , step 7 .

\section{BTEP 3:}

At the FTIR computer, restart the win-IR program by clicking the "SPFTIRII" button.

\section{BTFP 4:}

Verify that the file name for the first sample at the lower

left hand corner of the screen matched today's date and

starts with the interferogram index number "RUN ID" listed in section 4.5 .2 , step 8 .

\section{BTEP $5:$}

Wait until the index number of the last 3 digits in the file name located at the lower left corner of Win-IR screen indicates 013 and proceed prompthly with the next step.

\section{BTEP $6:$}

During a scan, depress the Esc key, to stop the scaning process.

BTEP 7:

4 At the GCS1HOST computer, use Text Editor to view and verify the report file "D: |FTIR/YMMDDIRIYMMDDIR. RPT for continuous record index after the system interruption.

\subsubsection{Day Change Tost}

\section{TEP 1:}

To simulate the day change, set the GCS1HOST and the FTIR systems time to $23: 55$. 
TSP 28

Restart the win-IR program by clicking the "SPFTIRII" button.

SLIP 38

Once scanning starts, monitor the lower left hand corner of the screen for the date change in file name. The file name "Y-MM-DD-*" " and the interferogram index number "ff

STHP 48

Monitor until the interferogram index number of the last 3 digits in the file name indicates 003 before proceeding.

STHP 5:

During a scan, depress the Escape key twice, to stop the scaning process.

Bपy? 68

In GCS1HOST computer, use File Manager to verify that the date has changed and that the new subdirectory

"D: IFTIR/YMMDDIR" for the new date has been created.

\section{BTEP 78}

Use File Manager to verify that under a new subdirectory "D: IFTIR\YMMDDIR", new ".RPT and. SPC" files have been created with the new name based on the new date.

STEP 88

At the GCS1HOST computer, use file Manager to remove al1 subdirectories and files under the directory "D: FTIR".

S2मP 98

Reset the GCS1HOST system date and time back to current date and time.

\section{TFP 10:}

At the FTIR computer, use File Manager to remove all files under the directory "C: IFTIR".

\section{BTHP $11:$}

Reset the FTIR system date and time back to current date and time.

\subsubsection{Transfer Data Acoross Hay}

The following series of steps are designed to simulate the condition to verify the data tranfer function in the software. The test data set was created and stored in the directory "D: IFTIR.TST" prior to the test. The test data set contains the report file "60208IR.RPT" and all the associated interferograms. 
BTEP 1:

At GCS1HOST computer, use File Manager to verify that the report and all the associated interferogram files exist in the test directory "D:|FTIR.TST\60208IR".

8THP 2:

Use File Manager to verify the network "H:|FTIR|60208IR.ZIP" and the "H:\FTIR\60208IR.RPT" files do not exist.

\section{THP 38}

Use File Manager to copy the subdirectory and all files under "D: IFTIR.TST" into the directory "D: IFTIR".

\section{BTEP 48}

Use Text Editor to examine and verify the parameters in "C: \BIN\FTIR_ZIP.INI" file. If any of the parameters in the FTIR_ZIP.INI file do not match the parameters listed below, correct them and save the corrected parameters back to "C:\BIN\FTIR_ZIP.INI" file.

\ব data files path $=$ D: |ftir|

'Y zip_file_path = H:|ftir|

NOTE: Ignore the comment in the $c: \mid B I N \backslash F T I R Z I P . I N I$ file.

\section{TFP 5:}

Under Program Manager set the date on the GCS1HOST system to 02-09-1996.

\section{TEP 6:}

In File Manager, close all directory windows before starting the zip and transfer process.

Run the C: IBIN\FTIRZIP.EXE program.

BTEP $7:$

Use File Manager to verify that the files

"H:|FTIR\60208IR.ZIP" and "H:|FTIR\60208IR.RPT" exists.

\section{BपFP 88}

Use file Manager to verify that the "D:|FTIR/60208IR"

directory was removed.

\section{TEP 98}

Run winzip to open and view the contents in

"H:|FTIR\60208IR.ZIP" file.

\section{BTEP 108}

Use File Manager to remove the "H:|FTIR\60208IR.zIP" and the "H: IFTIR\60208IR.RPT" files.

8TEP 128

Under Program Manager set the date on the GCS1HOST system back to the current date. 


\subsubsection{Network Failure Tast}

8TSP 1:

At the FTIR computer, use File Manager to remove all files under the $C: \backslash F T I R$ directory if they exist.

BTFP 2:

At the GCS1HOST computer, terminate all active applications and close all windows under Program Manager.

\section{TFP 3:}

start the FTIR program by clicking on the SPFTIRII button.

\section{BTEP 4:}

Once scanning starts, check the lower left hand corner of the screen for the file name. It should match today's date and starts with the index 001 for the first sample.

BTEP $5:$

Wait until the index number of the last 3 digits in the file name located at the lower left corner of win-IR screen indicates 005 and proceed prompthly with the next step.

8TEP 6:

NOTE: In this step, bring File Manager to the foreground in the FTIR computer while the win-IR program is doing scans. When calculations begin, win-IR will return to the foreground. Do not inhibit this swap. Switch back only when scans start again.

1) To simulate the local network problem, disconnect "FTIR" from "GCS1hOST" by breaking the local network connection at the "FTIR" drive D. To do this click on the "Disconnect" button in File Manager. Select the connection to the GCS1HOST computer "D: \|GCS1HOST\FTIR".

BTEP B:

Verify that the Win-IR program is not locked up.

BTEP 9:

Wait until win-IR has finished taking four to five more samples. During a scan, depress the Escape key, to stop the scaning process.

BTFP $10:$

Use File Manager to verify that the ".SPC" files and the ".RPT" file are stored locally at the FTIR computers under "C: $\backslash$ FTIR" directory.

\section{BTEP 11:}

$M$ Use File Manager to remove all interferogram files ".SPC" in the directory "C: $\backslash$ FTIR". 
BTEP 128

$M$ To manualiy re-establish the FTIR/GCS1HOST link, use File Manager to reconnect the network drive $D$ to "D: \|GCS1HOST\FTIR". .

\section{BTEP 138}

$M$ To simulate the HLAN network outage, disconnect "IABHOST" from "GCS1HOST" by breaking the HLAN network connection at GCS1HOST. To do this click on the "disconnect" button in File Manager. Select the connection to the LABHOST computer "H: \\LABHOST\GCS1DATA".

\section{BTEP $14:$}

At GCS1HOST computer, use File Manager to verify that the report and the interferogram files exist in today's directory "D: IFTIR\YMIDDIR".

8TEP 15:

$M$ Under Program Manager set the date on GCS1HOST to the next day's date.

\section{BTEP $16:$}

$M$ To start the FTIR's zip and transfer process, run C: \BIN\FTIRZIP. EXE program. locally and then delete it.

\section{TEP 188}

\section{BTEP 19:}

Under Program Manager reset the date on GCS1HosT back to today's date.

\section{BTEP $20:$}

Use the File Manager to reconnect the network drive $\mathrm{H}$ "H: \|LABHOST\GCSIDATA".

\section{BTEP $21:$}

M Terminate all active applications and close all program groups in GCS1HOST and FTIR computers. 


\subsection{TEST APRROVAT AND ACCEPTAMCE}

x

The System Engineer/Test Director, by his or her signature below, states that the Gas Characterization system software complies with the design documents and is functional.

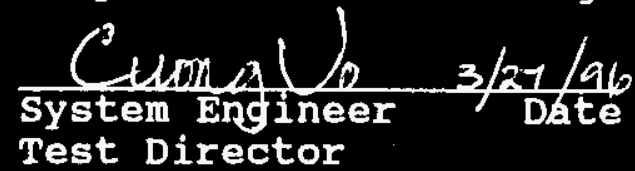

\subsection{TEST RECORD BABDTS}

\subsection{TEBT EXCEPTION BHFEY}

Test Exception Sheets are used to document exceptions to the test procedure. Actions taken regarding disposition are noted on the exception sheet. Typical dispositions are:

1. Test approved with exception (i.e. rerun of the acceptance test unnecessary).

2. Entire acceptance test to be repeated after the discrepancy has been corrected.

3. Acceptance Test Procedure step(s) affected to be repeated after the discrepancy has been corrected.

Test Exception Sheets are included in Appendix A.

\subsection{TEST LOG BAEET}

Test Log Sheets are used to document test start and stop times and to document any other notes concerning the execution of the Acceptance Test Procedure.

Test Log Sheets are included in Appendix B. 

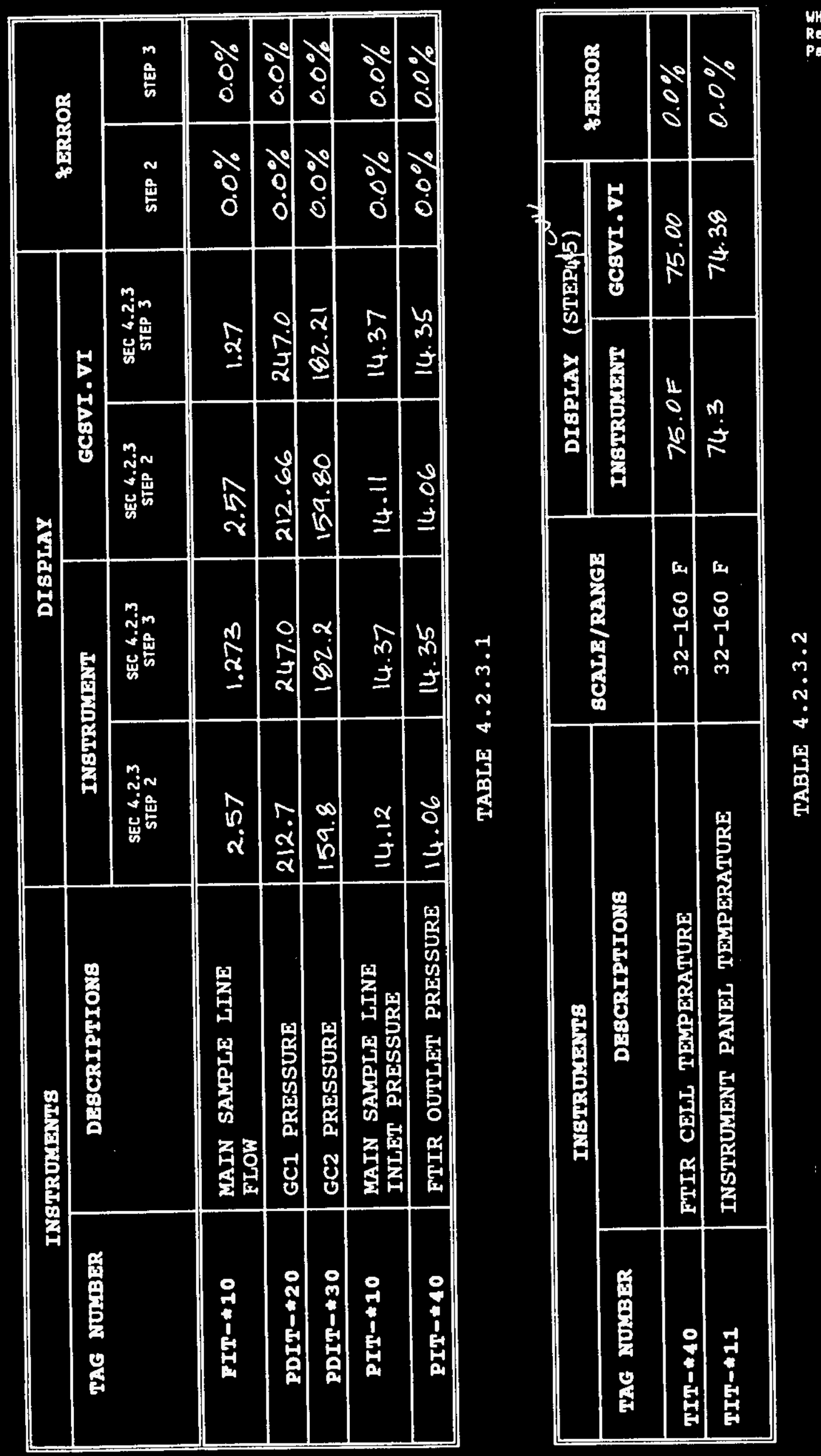

MHC-SD-WH-ATR-172

Rev. 0

Page 54

? 

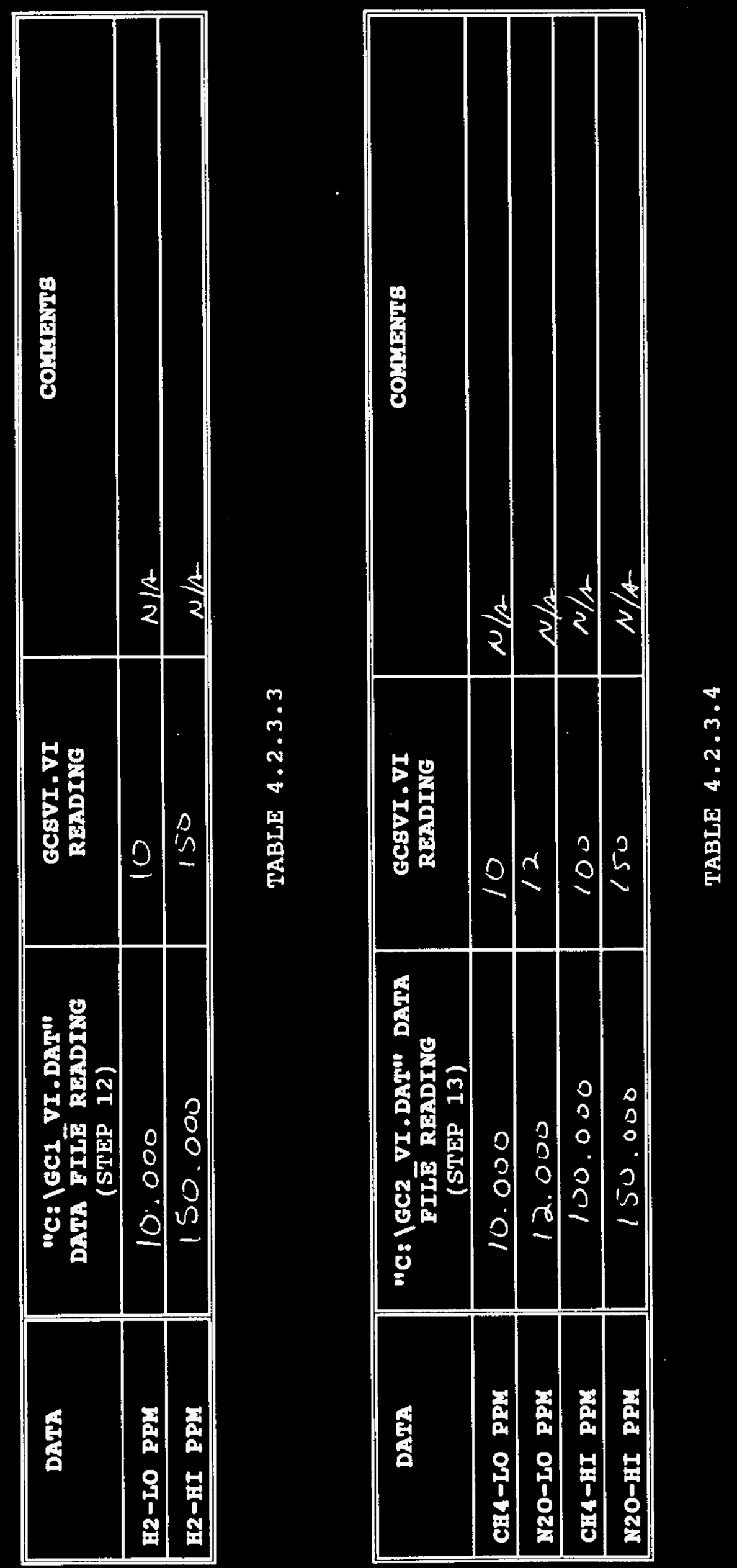

WHC-SD-MH-ATR-172

Rev. 0

Page 55 


$$
C_{2 / 28 / 96}
$$

PDIT- $* 30$

\begin{tabular}{|c|c|c|c|c|c|c|c|c|}
\hline DATE & TIME & $F I T-\star 10$ & PDIT $-\star 20$ & PDIT-420 & $P I T-\$ 10$ & $P I T-* 40$ & $T I T-40$ & $T I T-* 11$ \\
\hline & & & & & & & & \\
\hline
\end{tabular}

TABLE 4.2 .6 .1

\begin{tabular}{|c|c|c|c|c|c|c|c|c|c|}
\hline & \multicolumn{9}{|c|}{$\mathrm{CV}_{2 / 28 / 96}$} \\
\hline & DATE & TIXES & $F T P-* 10$ & PDIT- -20 & $\begin{array}{l}\text { PDIT-*20 } \\
\text { PDIT-*30 }\end{array}$ & $P I T-* 10$ & $P I T-* 40$ & $T I T-\$ 40$ & $T I T-\| 11$ \\
\hline $\begin{array}{l}\text { GCSVI . VI } \\
\text { READING }\end{array}$ & $2 / 28 / 96$ & 10:17 AN & 1.27 & 247.14 & 184.31 & 14.36 & 14.35 & 76.60 & 75.41 \\
\hline $\begin{array}{l}\text { INBTROMELY } \\
\text { READ OUT }\end{array}$ & $2 / 28 / 96$ & $10: 26 \mathrm{AM}$ & 1.27 & 247.16 & 184.33 & 14.36 & 14.35 & 77.00 & 75.81 \\
\hline
\end{tabular}

TABLE 4.2 .6 .2

\begin{tabular}{|c|c|c|c|c|}
\hline & \multicolumn{2}{|c|}{$\begin{array}{l}\text { CERTIFIFD BTANDARD } \\
\text { CAIIBRATIOA GAS }\end{array}$} & \multirow{2}{*}{$\begin{array}{l}\text { EZChrom } \\
\text { REDDING } \\
\text { (STEP 3) }\end{array}$} & \multirow[t]{2}{*}{ COMMANIS } \\
\hline & HOxINAT & ACrUaA & & \\
\hline H2-IO PPY & $100 \mathrm{PPH}$ & $101 \mathrm{epm}$ & 101.047 & $1 / 621327$ \\
\hline B2-BI PRY & $100 \mathrm{PPH}$ & $101 \mathrm{ppm}$ & 101.127 & $10 \% 21327$ \\
\hline
\end{tabular}

TABLE $4.3 \cdot 1.1$ 


\begin{tabular}{|c|c|c|c|c|c|c|}
\hline 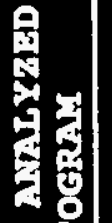 & $\begin{array}{l}4 \\
0 \\
8\end{array}$ & $\begin{array}{l}5 \\
5 \\
0 \\
0\end{array}$ & $\begin{array}{l}0 \\
5 \\
8 \\
8\end{array}$ & $\begin{array}{l}\overrightarrow{1} \\
0 \\
\dot{\gamma} \\
0\end{array}$ & $\begin{array}{r}r \\
\vdots \\
0\end{array}$ & $\frac{n}{\gamma}$ \\
\hline 量家 & $\begin{array}{l}9 \\
0 \\
0 \\
0\end{array}$ & $\begin{array}{l}5 \\
0 \\
0 \\
0 \\
0\end{array}$ & 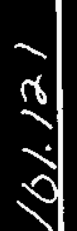 & $\begin{array}{l}3 \\
5 \\
0 \\
0 \\
0\end{array}$ & $\begin{array}{l}3 \\
\sigma \\
0 \\
0\end{array}$ & $\stackrel{0}{2}$ \\
\hline \multirow{2}{*}{ 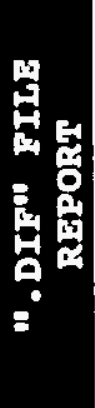 } & $\begin{array}{l}0 \\
0 \\
0\end{array}$ & $\begin{array}{l}0 \\
0 \\
0\end{array}$ & 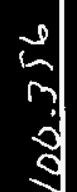 & $\begin{array}{l}\vec{v} \\
\dot{\gamma} \\
\dot{\gamma}\end{array}$ & $\begin{array}{l}\tilde{\gamma} \\
\hat{\gamma} \\
\partial\end{array}$ & $\frac{2}{2}$ \\
\hline & $\begin{array}{l}0 \\
0 \\
0 \\
0\end{array}$ & $\begin{array}{l}3 \\
0 \\
0\end{array}$ & $\frac{2}{\partial}$ & $\begin{array}{c}d \\
a \\
\vdots \\
\vdots \\
\vdots\end{array}$ & $\begin{array}{l}\frac{1}{3} \\
0 \\
3 \\
0\end{array}$ & $\frac{\partial}{3}$ \\
\hline \multirow{2}{*}{ 㝵 } & $\begin{array}{l}\text { 붕 } \\
\mathbf{8}\end{array}$ & $\approx$ & $\begin{array}{l}3 \\
\text { m } \\
8\end{array}$ & $\begin{array}{l}5 \\
0 \\
0\end{array}$ & $\begin{array}{l}r \\
\gamma \\
0\end{array}$ & $\frac{7}{3}$ \\
\hline & $\begin{array}{l}8 \\
0 \\
0\end{array}$ & $\begin{array}{l}3 \\
0 \\
0\end{array}$ & $\vec{\gamma}$ & $\begin{array}{c}d \\
0 \\
0 \\
0\end{array}$ & $\begin{array}{l}0 \\
\sigma \\
0 \\
0\end{array}$ & $\checkmark$ \\
\hline \multirow{3}{*}{ 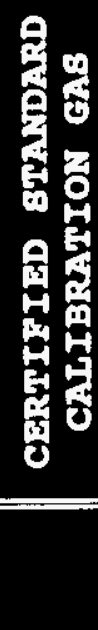 } & $\begin{array}{l}-4 \\
8 \\
8\end{array}$ & $\$$ & $\begin{array}{l}5 \\
\frac{1}{2} \\
0\end{array}$ & $\begin{array}{c}5 \\
a \\
0\end{array} \mid$ & $\begin{array}{l}\frac{5}{2} \\
\frac{2}{2}\end{array}$ & 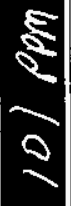 \\
\hline & $\begin{array}{l}0 \\
0 \\
8 \\
8\end{array}$ & 今a & $\frac{5}{8}$ & $\begin{array}{l}8 \\
\text { के } \\
-2\end{array}$ & $\frac{5}{2}$ & $\begin{array}{l}5 \\
2 \\
0 \\
-2\end{array}$ \\
\hline & 8 & $r$ & 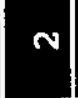 & $m$ & + & in \\
\hline
\end{tabular}

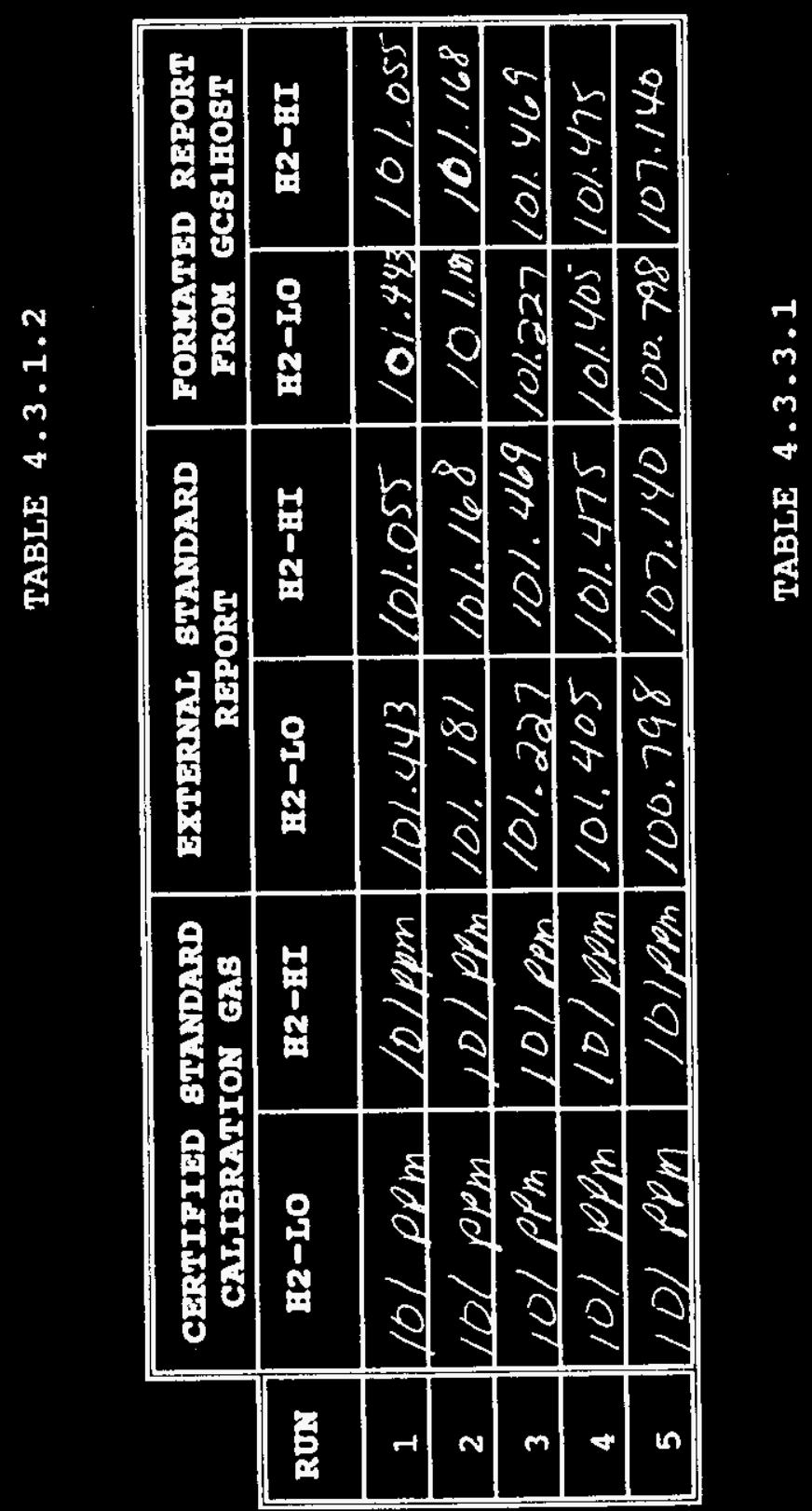


WHC-SD-MH-ATR-172

Rev. 0

Page 58
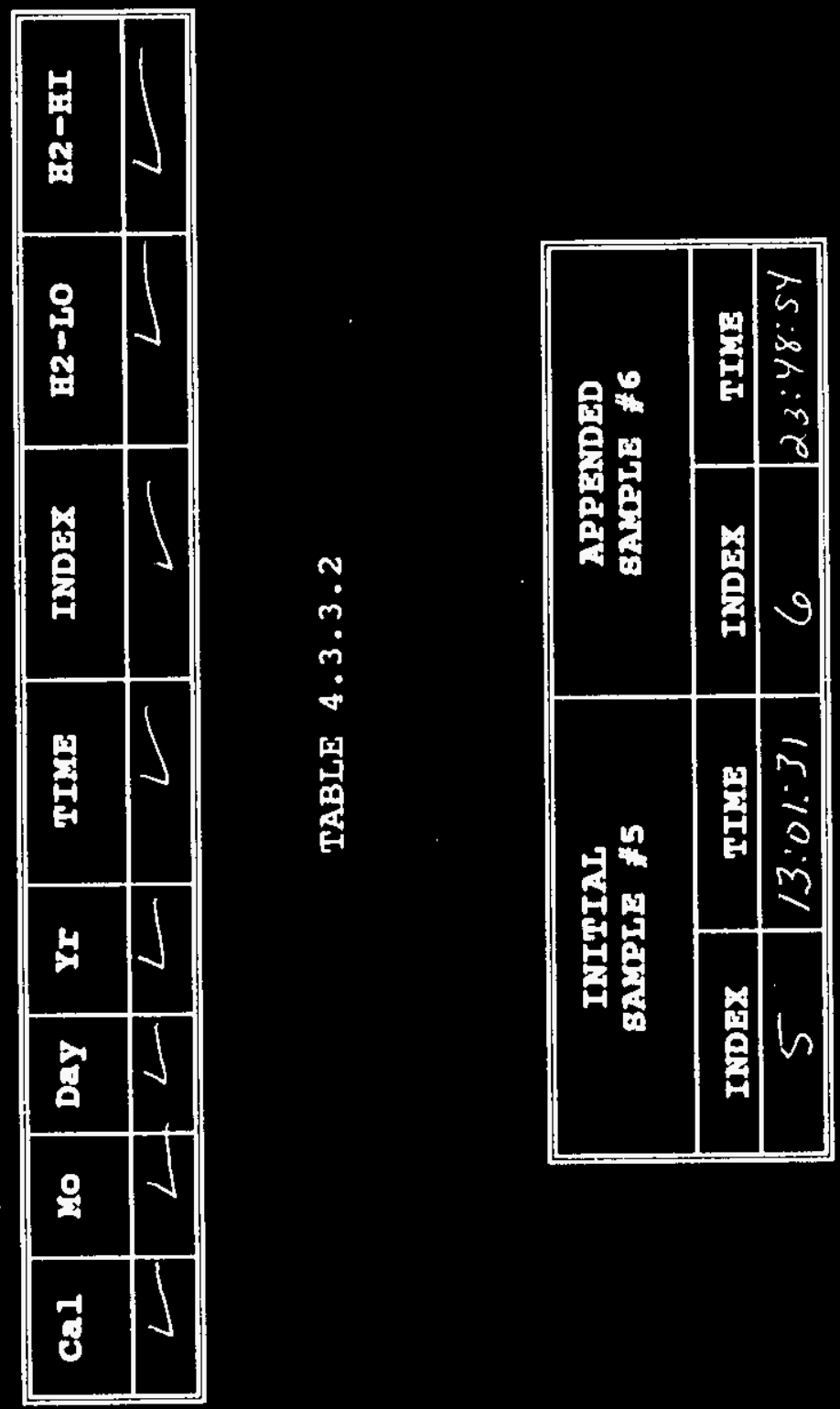

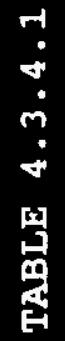


\{\}

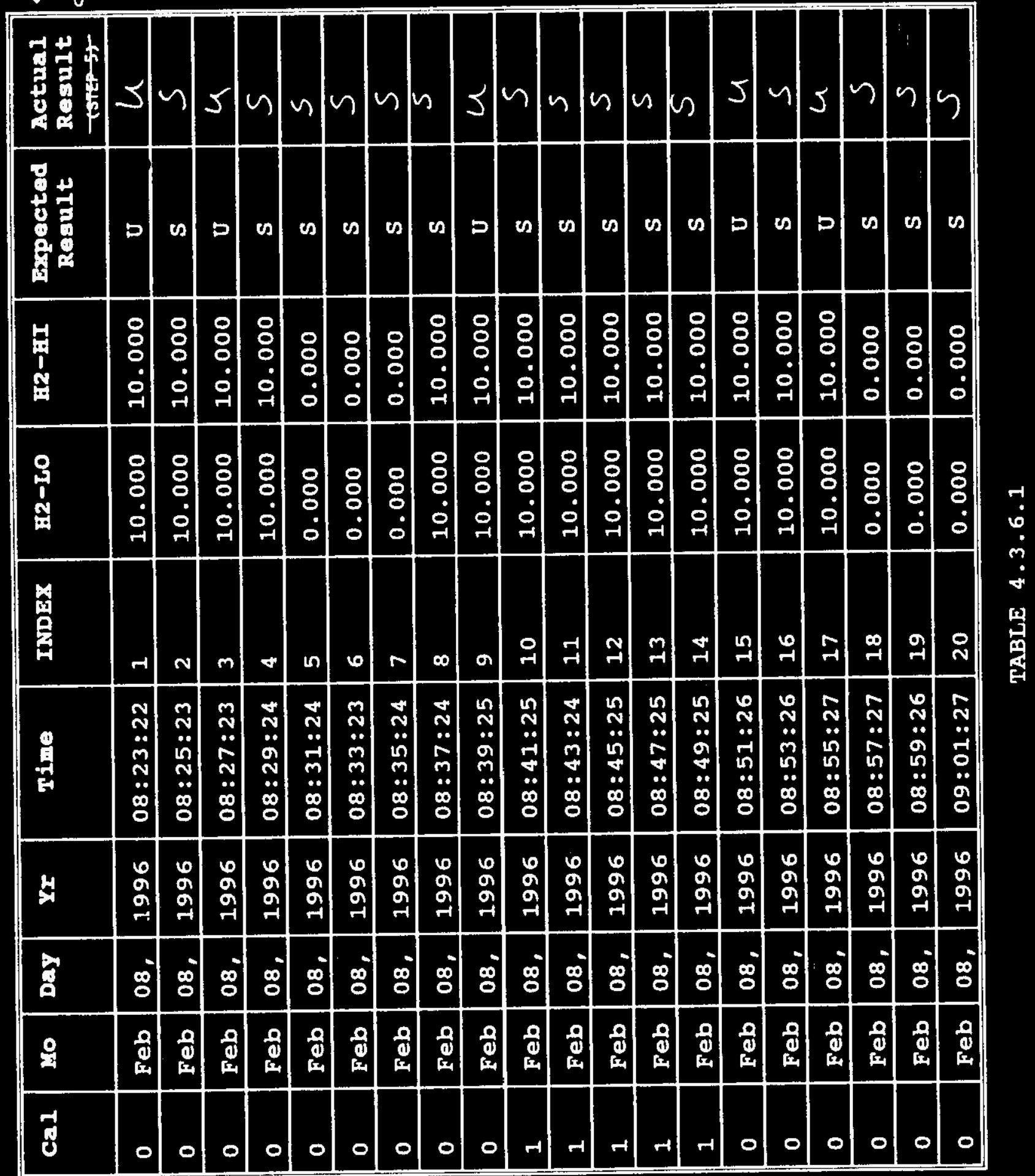




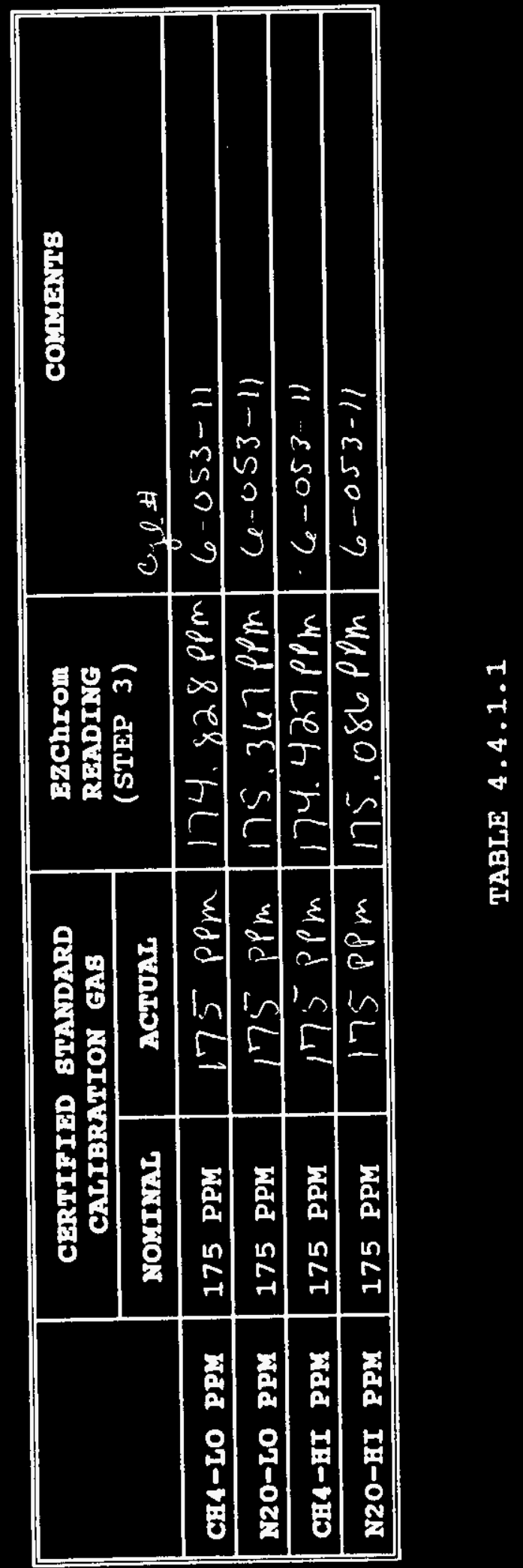




\begin{tabular}{|c|c|c|c|c|c|c|c|c|}
\hline \multirow[b]{2}{*}{ ROS } & \multicolumn{2}{|c|}{$\begin{array}{l}\text { CERTIFIED BTANDARD } \\
\text { CALIBRATION GAB }\end{array}$} & \multicolumn{2}{|c|}{$\begin{array}{l}\text { EXTERRMAL BTAMDARD } \\
\text { REPORT }\end{array}$} & \multicolumn{2}{|c|}{$\begin{array}{l}\text { ".DIF" FILE } \\
\text { REPORT }\end{array}$} & \multicolumn{2}{|c|}{$\begin{array}{c}\text { VAYUE FROY } \\
\text { NAAYZED } \\
\text { CHROMAPOCRAY }\end{array}$} \\
\hline & C:14-IO & \$20-LO & CR4-IO & $120-10$ & CH4-LO & S20-10 & CE14-LO & 370-10 \\
\hline 1 & 175 & 175 & 176.172 & 176.294 & 176.172 & 176.294 & 176,172 & 176.294 \\
\hline 2 & 175 & 175 & 176.008 & 176.286 & 176.008 & 176.286 & 176.008 & 176.286 \\
\hline 3 & 175 & 175 & 175.807 & 176.040 & 175.807 & 176,040 & 175.807 & 176.040 \\
\hline 4 & 175 & 175 & 175.749 & 175.917 & 175.749 & 175.917 & 175.749 & 175.917 \\
\hline 5 & 175 & 175 & 175.655 & 176.052 & 175.655 & 176.052 & 175.655 & 176.052 \\
\hline
\end{tabular}

TABLE 4.4.1.2 (Channel A)

\begin{tabular}{|c|c|c|c|c|c|c|c|c|}
\hline \multirow[b]{2}{*}{ ROS } & \multicolumn{2}{|c|}{$\begin{array}{l}\text { CERTIIIED BTANDARD } \\
\text { CALIBRATIOU GAB }\end{array}$} & \multicolumn{2}{|c|}{$\begin{array}{c}\text { EXYWGRWAY BTANDARD } \\
\text { REPORT }\end{array}$} & \multicolumn{2}{|c|}{$\begin{array}{l}\text { ".DIF" PIIE } \\
\text { REPORT }\end{array}$} & \multicolumn{2}{|c|}{ 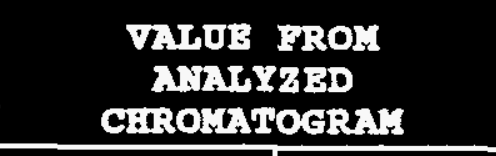 } \\
\hline & CE4-HI & N20-EI & CH4-HI & N20-HI & CEA-III & N20-HI & CBA-BI & X20-III \\
\hline 1 & 175 & 175 & 174.930 & 175.741 & 174930 & 175.741 & 174.930 & 175.741 \\
\hline 2 & 175 & 175 & 175.022 & 175.349 & 175.022 & 175.349 & 175.022 & 175349 \\
\hline 3 & 175 & 125 & 175.024 & 175.379 & 175.024 & 175.379 & 175.024 & 175.375 \\
\hline 4 & 175 & 175 & 175.088 & 175.660 & 175.088 & 175,660 & 175.088 & 175.660 \\
\hline 5 & 175 & 175 & 174.736 & 175.433 & 174.736 & 25.433 & 174.736 & 175.433 \\
\hline
\end{tabular}

TABLE 4.4.1.2 (Channel B) 


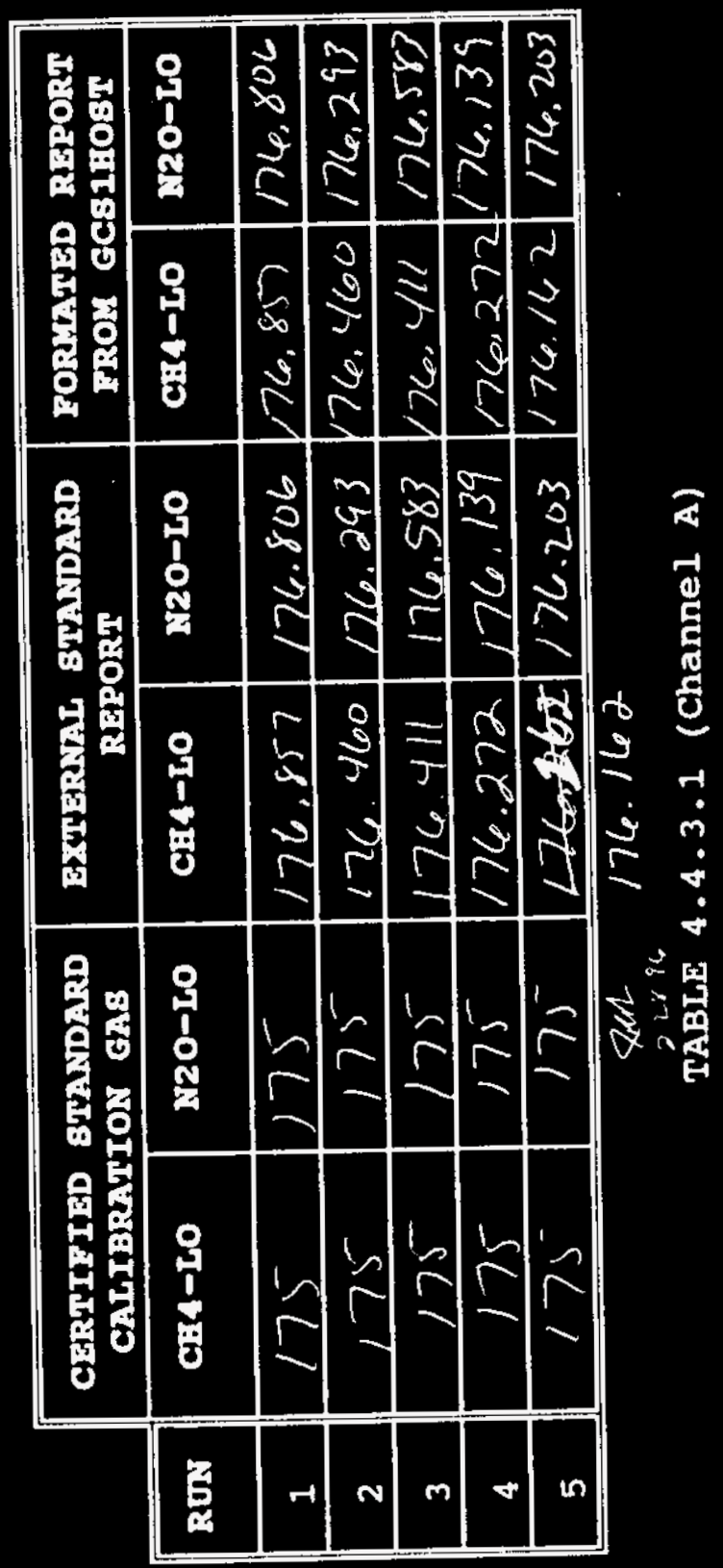

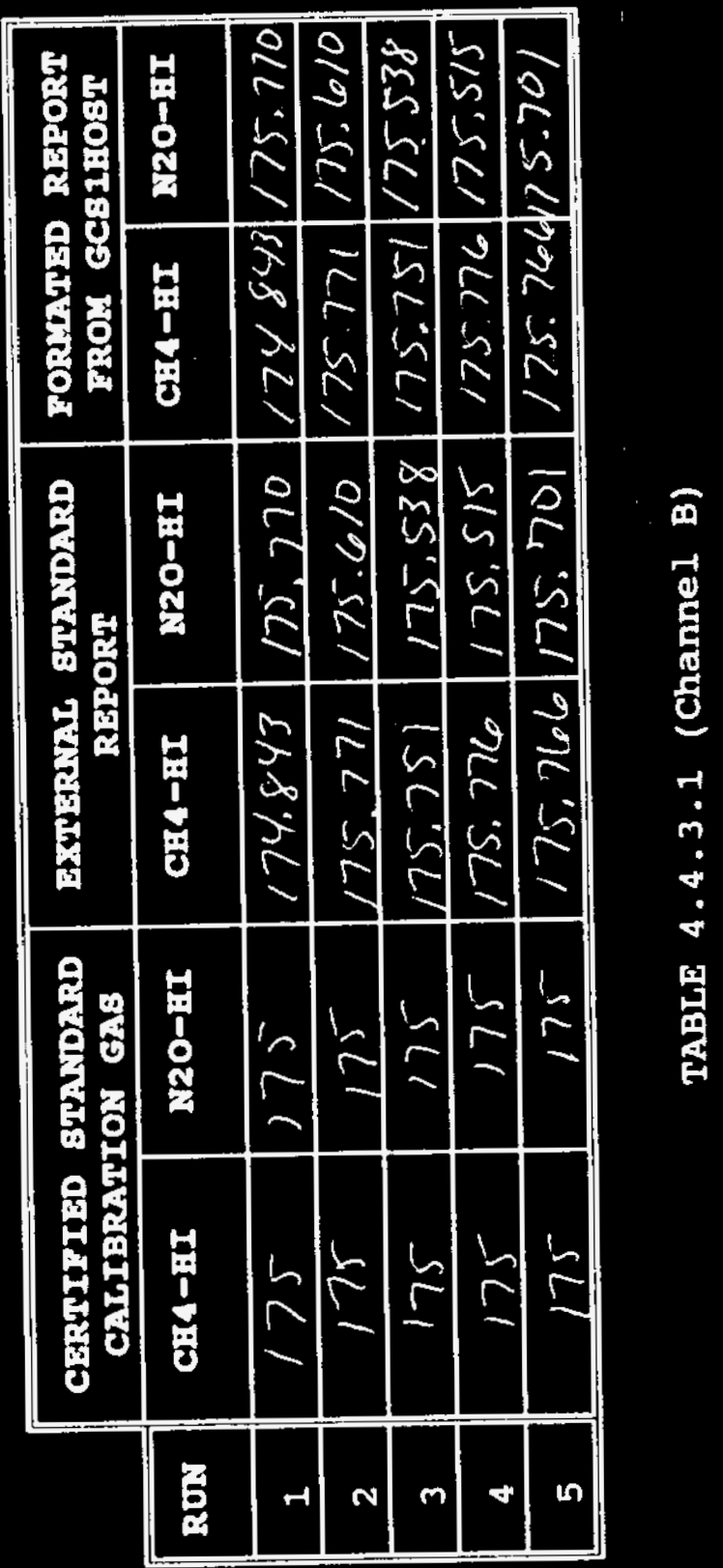


WHC-SD-LH-ATR-172

Rev. 0

paqe 63

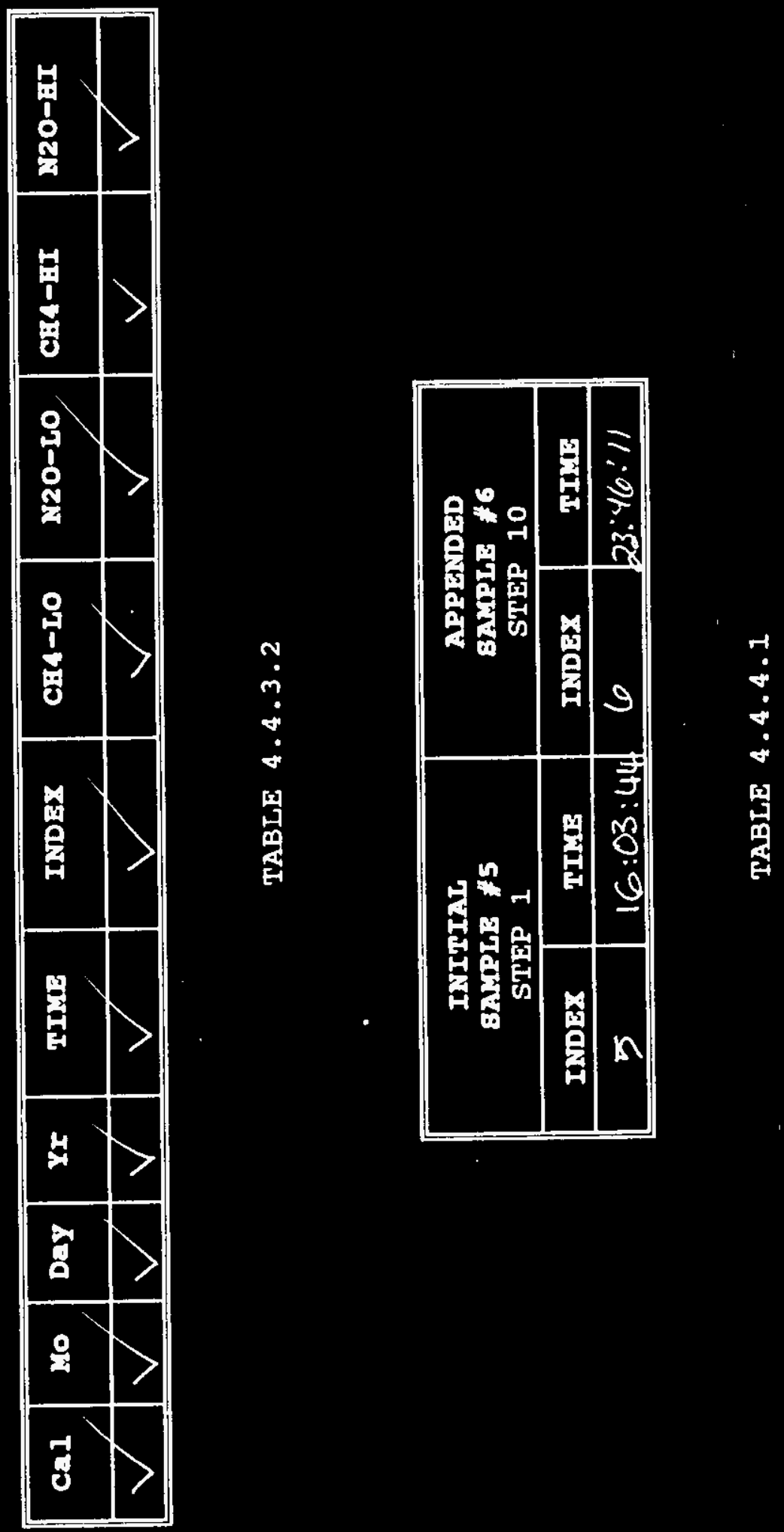




\begin{tabular}{|c|c|c|c|c|c|c|c|c|c|c|c|}
\hline $\operatorname{col}$ & xo & Day & $\mathbf{Y r}$ & Time & IXDEX & C:14-IO & $2120-10$ & C:L4-HI & H20-II & $\begin{array}{l}\text { Bispected } \\
\text { Result }\end{array}$ & $\begin{array}{l}\text { Actual } \\
\text { Result }\end{array}$ \\
\hline 0 & Feb & 08, & 1996 & $08: 24: 13$ & 1 & 10.000 & 10.000 & 10.000 & 10.000 & $\mathbf{U}$ & 1 \\
\hline 0 & Feb & 08 & 1996 & $08: 26: 13$ & 2 & 10.000 & 10.000 & 10.000 & 10.000 & $\mathbf{s}$ & 5 \\
\hline 0 & Feb & 08, & 1996 & $08: 28: 13$ & 3 & 10.000 & 10.000 & 10.000 & 10.000 & $\mathbf{U}$ & $u$ \\
\hline 0 & Feb & 08 & 1996 & $08: 30: 14$ & 4 & 10.000 & 10.000 & 10.000 & 10.000 & $s$ & 5 \\
\hline 0 & Feb & 08, & 1996 & $08: 32: 14$ & 5 & 0.000 & 0.000 & 0.000 & 0.000 & $\mathbf{s}$ & 5 \\
\hline 0 & Feb & 08, & 1996 & $08: 34: 13$ & 6 & 0.000 & 0.000 & 0.000 & 0.000 & $\mathbf{s}$ & 5 \\
\hline 0 & Feb & 08 & 1996 & $08: 36: 14$ & 7 & 0.000 & 0.000 & 0.000 & 0.000 & $\mathbf{s}$ & $S$ \\
\hline 0 & Feb & 08, & 1996 & $08: 38: 14$ & 8 & 10.000 & 10.000 & 10.000 & 10.000 & $\mathbf{s}$ & $S$ \\
\hline 0 & Feb & 08 & 1996 & $08: 40: 14$ & 9 & 10.000 & 10.000 & 10.000 & 10.000 & $\mathbf{U}$ & 4 \\
\hline 1 & Feb & 08, & 1996 & $08: 42: 14$ & 10 & 10.000 & 10.000 & 10.000 & 10.000 & $\mathbf{s}$ & $S$ \\
\hline 1 & Feb & 08, & 1996 & $08: 44: 15$ & 11 & 10.000 & 10.000 & 10.000 & 10.000 & $\mathbf{s}$ & 5 \\
\hline 1 & Feb & 08, & 1996 & $08: 46: 15$ & 12 & 10.000 & 10.000 & 10.000 & 10.000 & $\mathbf{s}$ & $S$ \\
\hline 1 & Feb & 08 & 1996 & $08: 48: 15$ & 13 & 10.000 & 10.000 & 10.000 & 10.000 & $\mathbf{s}$ & 5 \\
\hline 1 & Feb & 08, & 1996 & $08: 50: 15$ & 14 & 10.000 & 10.000 & 10.000 & 10.000 & $\mathbf{s}$ & 5 \\
\hline 0 & Feb & 08, & 1996 & $.08: 52: 16$ & 15 & 10.000 & 10.000 & 10.000 & 10.000 & $\mathbf{U}$ & $u$ \\
\hline 0 & Feb & 08, & 1996 & $08: 54: 16$ & 16 & 10.000 & 10.000 & 10.000 & 10.000 & $\mathbf{s}$ & $S$ \\
\hline 0 & Feb & 08 , & 1996 & $08: 56: 16$ & 17 & 10.000 & 10.000 & 10.000 & 10.000 & $\mathbf{U}$ & $u$ \\
\hline 0 & Feb & 08, & 1996 & $08: 58: 17$ & 18 & 0.000 & 0.000 & 0.000 & 0.000 & $\mathbf{s}$ & 5 \\
\hline 0 & Feb & 08, & 1996 & $09: 00: 17$ & 19 & 0.000 & 0.000 & 0.000 & 0.000 & $\mathbf{s}$ & $S$ \\
\hline 0 & Feb & 08, & 1996 & $09: 02: 17$ & 20 & 0.000 & 0.000 & 0.000 & 0.000 & $\mathbf{s}$ & $=$ \\
\hline
\end{tabular}



APPFEI
TPEST
BXCEPIIOT
BEBETS
$10 F 4$

TEST EXCEPYION BHEET

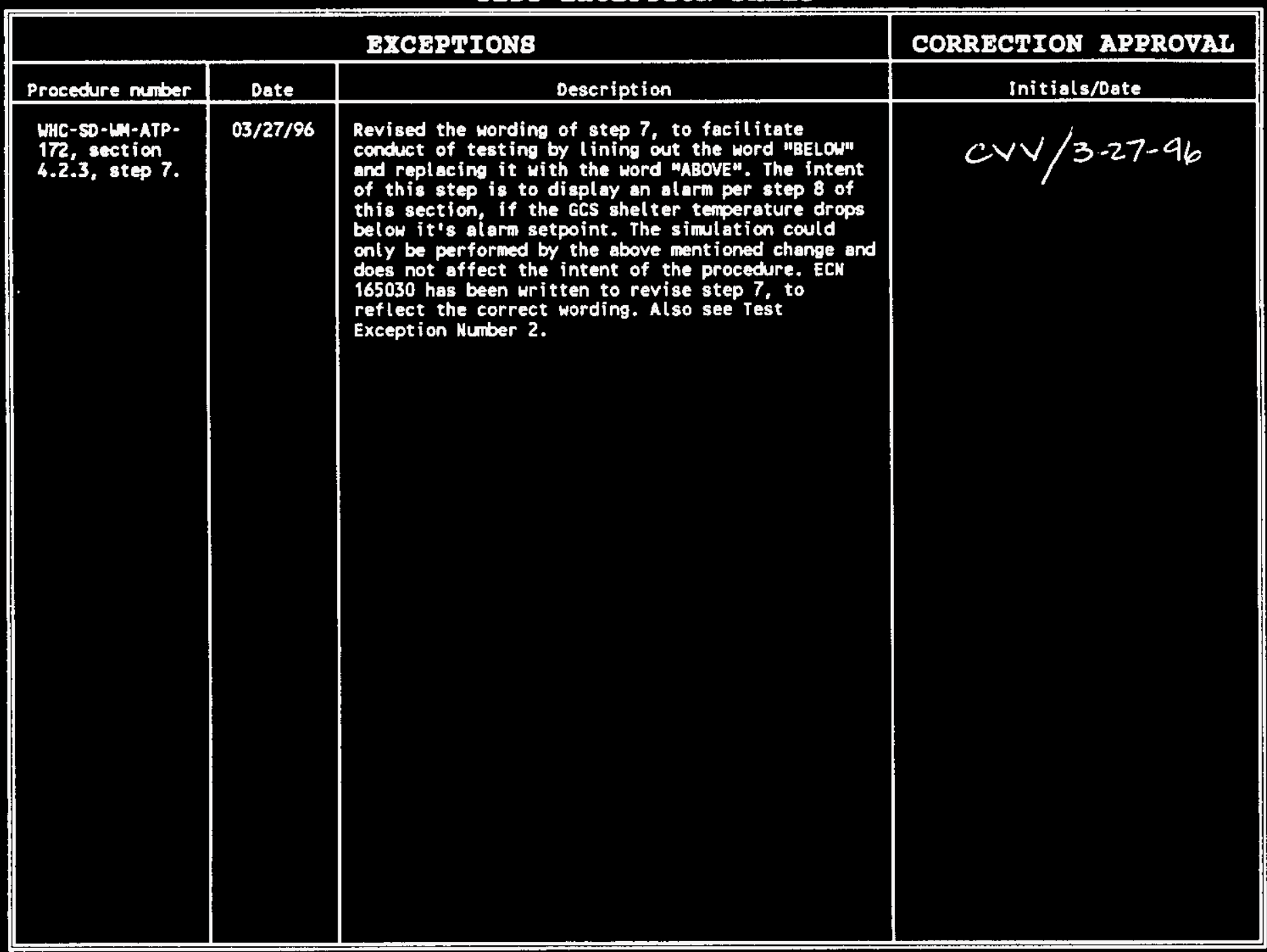

EXCEPTION NUMBER: 1

OBJECTING: JR.BunCN

Test Engineer

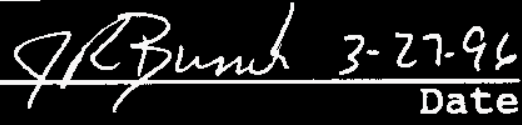

ACCEPTABLE RETEST PERFORMED:

$N / A$

$C V Y$

$3-27-9 b_{2}$

Test Director

Date

System Engineer

EXCEPTION RESOLVED:

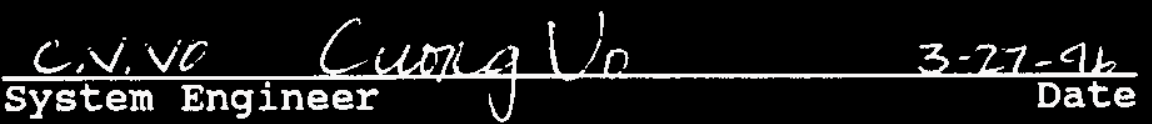


TEBT EXCEPTION BEFET

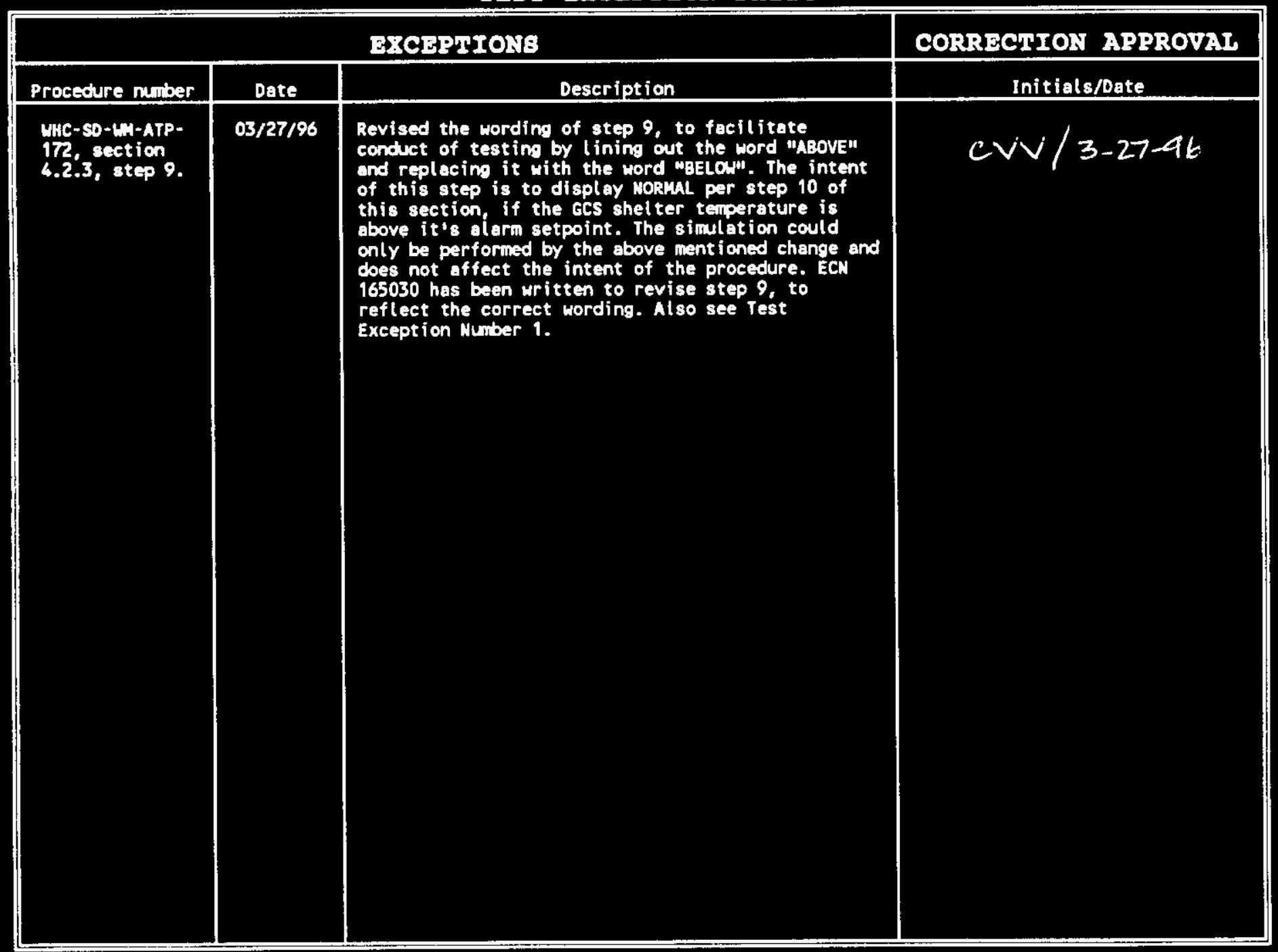

EXCEPTION NUMBER: 2

OBJECTING:

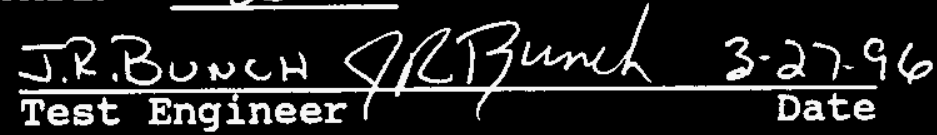
ACCEPTABLE RETEST PERFORMED: $N / A$ Test Director

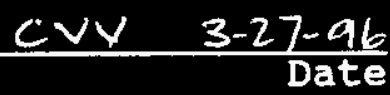 System Engineer

EXCEPTION RESOLVED:

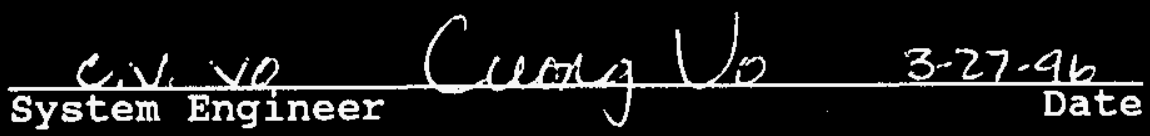


WHC-SD-LM-ATR-172

Rev. 0

Pare 65,2

APPESDIX A: TEST EXCEPTION BHEATB

3 of 4

TEST BXCEPITON BHBET

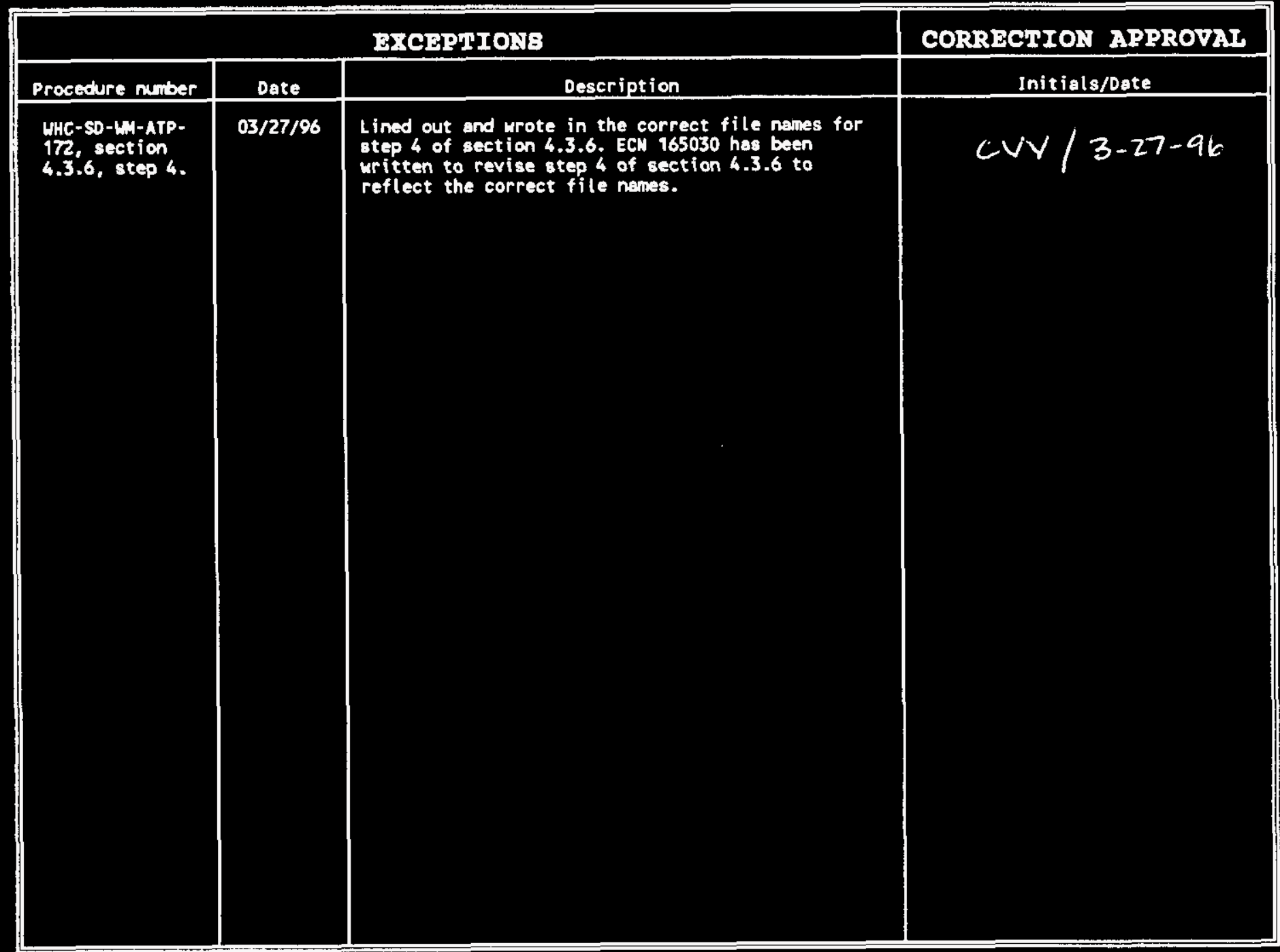

EXCEPTION NUMBER:

3

OBJECTING:

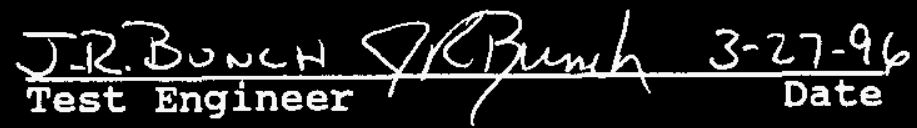

ACCEPTABLE RETEST PERFORMED: $\begin{array}{lll}\mathrm{N} / \mathrm{A} & \mathrm{CV} & 3-27-96 \\ \begin{array}{l}\text { Test Director } \\ \text { System Engineer }\end{array} & & \text { Date }\end{array}$

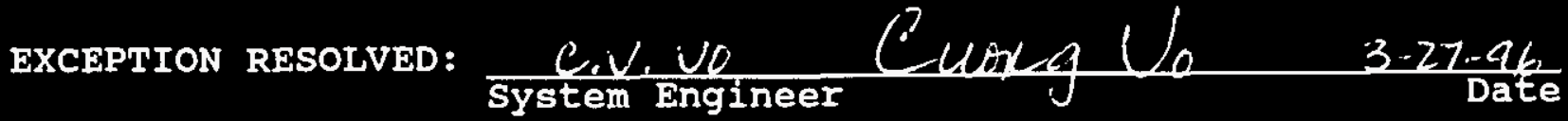


UHC-SD-LH-ATR-172

Rev. 0

Page 65. 3

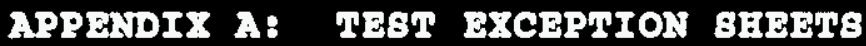

4 OF 4

TaBY GXCEPTION BREET

\begin{tabular}{|c|c|c|c|}
\hline \multicolumn{3}{|r|}{ BXCFPTIONA } & CORRBCIION APRROVAT \\
\hline Procedure number & Date & Description & Initials/Date \\
\hline $\begin{array}{l}\text { HHC-SD-WN-ATP- } \\
\text { 172, section } \\
4.4 .6, \text { step } 4 .\end{array}$ & $03 / 27 / 96$ & $\begin{array}{l}\text { Lined out and wrote in the correct file nanes for } \\
\text { step } 4 \text { of section } 4.4 .6 \text {. ECN } 165030 \text { has been } \\
\text { uritten to revise step } 4 \text { of section } 4.4 .6 \text { to } \\
\text { reflect the correct file nanes. }\end{array}$ & $c \vee v / 3-27-96$ \\
\hline
\end{tabular}

EXCEPTION NUMBER: 4

obJecting: $\frac{\text { JRBunch }}{\text { Test Engineer }} \frac{3-27-96}{\text { Date }}$

ACCEPTABLE RETEST PERFORMED:

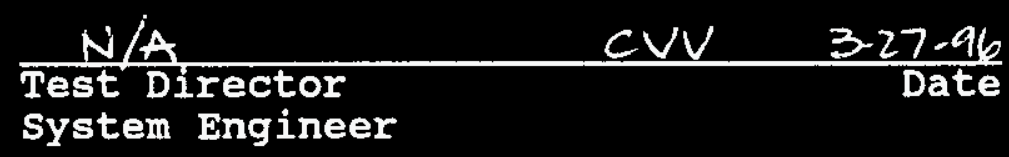

EXCEPTION RESOLVED:

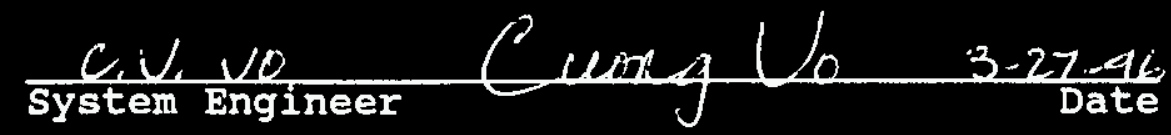




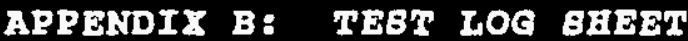

THET LOC

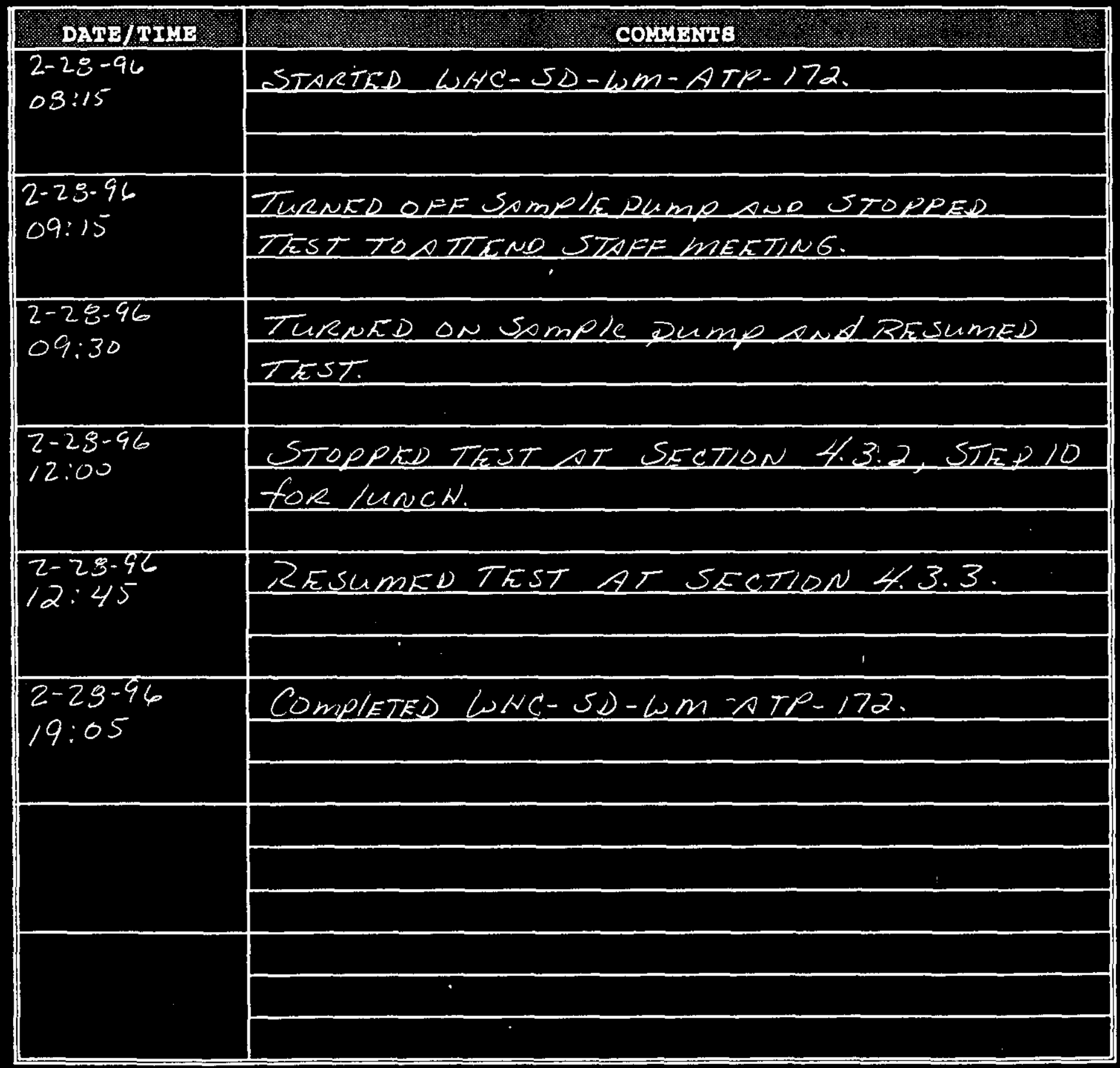




\section{DISTRIBUTION SHEET}

\begin{tabular}{|c|c|c|c|c|c|c|}
\hline \multirow{2}{*}{\multicolumn{2}{|c|}{$\begin{array}{l}\text { To } \\
\text { DISTRIBUTION }\end{array}$}} & \multirow{2}{*}{\multicolumn{3}{|c|}{$\begin{array}{l}\text { From } \\
\text { Characterization Monitoring } \\
\text { Development }\end{array}$}} & \multicolumn{2}{|l|}{ Page 1 of 1} \\
\hline & & & & & \multicolumn{2}{|c|}{ Date March 27, 1996} \\
\hline \multirow{2}{*}{\multicolumn{5}{|c|}{$\begin{array}{l}\text { Project Title/Work Order } \\
\text { 95C-EWW-451, Tank Character }\end{array}$}} & \multirow{2}{*}{\multicolumn{2}{|c|}{$\begin{array}{ll}\text { EDT No. } & 600179 \\
\text { ECN No. } & \text { N/A }\end{array}$}} \\
\hline & & & & & & \\
\hline \multicolumn{2}{|r|}{ Name } & MSIN & $\begin{array}{l}\text { Text } \\
\text { With All } \\
\text { Attach. }\end{array}$ & Text Only & $\begin{array}{l}\text { Attach./ } \\
\text { Appendix } \\
\text { Only }\end{array}$ & $\begin{array}{l}\text { EDT/ECN } \\
\text { Only }\end{array}$ \\
\hline $\begin{array}{l}\text { JR Bunch } \\
\text { DB Engelman } \\
\text { GD Johnson } \\
\text { S Kanjilal } \\
\text { JW Lentsch } \\
\text { WE Meeusen } \\
\text { CA Sams } \\
\text { TC Schneider } \\
\text { DD Tate } \\
\text { CV Vo } \\
\text { KA White } \\
\text { Central Files }\end{array}$ & $\begin{array}{l} \\
(2) \\
(2)\end{array}$ & $\begin{array}{l}\text { L6-37 } \\
\text { L6-37 } \\
\text { S7-15 } \\
\text { L6-37 } \\
\text { S7-15 } \\
\text { S5-05 } \\
\text { S5-13 } \\
\text { L6-37 } \\
\text { L6-37 } \\
\text { L6-37 } \\
\text { S5-13 } \\
\text { A3-88 }\end{array}$ & $\begin{array}{l}X \\
X \\
X \\
X\end{array}$ & & & $\begin{array}{l}X \\
X \\
X \\
X \\
X\end{array}$ \\
\hline
\end{tabular}

